\title{
From a Symptom-Based to a Mechanism-Based Pharmacotherapeutic Treatment in Complex Regional Pain Syndrome
}

\author{
Thomas J. P. Mangnus ${ }^{1}$ (1) $\cdot$ Krishna D. Bharwani $^{1} \cdot$ Maaike Dirckx $^{1} \cdot$ Frank J. P. M. Huygen ${ }^{1}$
}

Accepted: 7 February 2022 / Published online: 5 March 2022

(c) The Author(s) 2022

\begin{abstract}
Complex regional pain syndrome (CRPS) is a debilitating painful condition of a distal extremity that can develop after tissue damage. CRPS is thought to be a multimechanism syndrome and ideally the most prominent mechanism(s) should be targeted by drugs in an individually tailored manner. This review gives an overview of the action and evidence of current and future pharmacotherapeutic options for CRPS. The available options are grouped in four categories by their therapeutic actions on the CRPS mechanisms, i.e. inflammation, central sensitisation, vasomotor disturbances and motor disturbances. More knowledge about the underlying mechanisms of CRPS helps to specifically target important CRPS mechanisms. In the future, objective biomarkers could potentially aid in selecting appropriate mechanism-based drugs in order to increase the effectiveness of CRPS treatment. Using this approach, current and future pharmacotherapeutic options for CRPS should be studied in multicentre trials to prove their efficacy. The ultimate goal is to shift the symptom-based selection of therapy into a mechanism-based selection of therapy in CRPS.
\end{abstract}

\section{Introduction}

Complex regional pain syndrome (CRPS) is a painful condition of a distal extremity that can develop after tissue damage [1]. Although spontaneous onset of CRPS has been reported [2], tissue damage is typically the initial trigger for the development of CRPS [3]. CRPS is usually initiated by fracture, followed by blunt trauma and surgery [3-5]. If not appropriately treated, CRPS can result in a devastating loss of function of the affected extremity and have a significant impact on the social well-being of patients [6]. The incidence of CRPS has been reported to range from 5.5 per 100,000 person-years in Olmsted County in the United States (US) [5] to 26.2 per 100,000 person-years in

Thomas J. P. Mangnus

t.mangnus@ersmusmc.nl

Krishna D. Bharwani

bharwani.kd@gmail.com

Maaike Dirckx

m.dirckx@erasmusmc.nl

Frank J. P. M. Huygen

f.huygen@erasmusmc.nl

1 Department of Anesthesiology, Center for Pain Medicine, Erasmus MC University Medical Center, Dr. Molewaterplein 40, 3015 GD Rotterdam, The Netherlands
The Netherlands [6]. CRPS can occur in both children and adults $[3,5]$. The mean age of onset ranges between 47 and 53 years and women are more prone to develop CRPS than men $[3,5]$.

A diagnosis of CRPS is made on the basis of clinical criteria. Additional laboratory or imaging tests may be useful to differentially exclude other causes for the clinical picture $[7,8]$. After other diseases in the differential diagnoses are excluded, CRPS can be diagnosed by history taking and physical examination [8]. During history taking, the most universal symptom of CRPS patients is continuous pain. Although various criteria for the diagnosis for CRPS exist $[1,8,9]$, the syndrome is nowadays preferably diagnosed using the new International Association for the Study of Pain (IASP) clinical diagnostic criteria for CRPS [8]. These diagnostic criteria have recently been updated with pragmatic alterations in the CRPS assessment instructions [10]. To fulfil these CRPS diagnostic criteria, patients have to experience several sensory, vasomotor, sudomotor, motor, or trophic disturbances and have to suffer continuous pain that is disproportionate to the inciting tissue damage $[8,10]$. Of note, CRPS symptoms and signs can change during the course of the syndrome $[1,10]$.

Historically, pain physicians treated CRPS pain in a symptom-based manner and treatment was mostly on a trialand-error basis. Interestingly, there is no evidence that common pain medication such as acetaminophen, non-steroidal 


\section{Key Points}

Complex regional pain syndrome (CRPS) is a multimechanism syndrome, and the most prominent mechanism(s) of CRPS should be targeted by drugs in an individually tailored manner.

Pharmacotherapeutic treatment options for CRPS can be categorised into four groups based on the mechanisms they target: (1) inflammation; (2) peripheral and central sensitisation; (3) vasomotor disturbances; and; (4) motor disturbances.

Increasing knowledge about underlying mechanisms and diagnostic tests to differentiate between CRPS mechanisms will help to shift the symptom-based selection of therapy into a mechanism-based selection of therapy.

anti-inflammatory drugs (NSAIDs) and opioids are effective in CRPS [11, 12]. In the search to select more specific therapies, Bruehl et al. suggested to differentiate between CRPS phenotypes using the most prominent signs and symptoms present at history taking and physical examination [13]. In a cluster analysis study, Bruehl et al. suggested three possible phenotypes: (1) a 'florid' CRPS presentation as described by Gibbons and Wilson [14]; (2) predominant neuropathic pain/ sensory abnormalities; and (3) predominant vasomotor disturbances [13]. We believe that there is a fourth phenotype that covers predominant motor disturbances in CRPS, such as dystonia. The motor disturbance phenotype was possibly not found in the study of Bruehl et al. [13] because of the relatively low sample size. The suggested four phenotypes could be treated with specific drugs. For example, patients with vasomotor disturbances phenotype with a predominantly cold limb could be treated with a vasodilator [7, 13]. Furthermore, for patients with a neuropathic pain phenotype with prevalent signs of allodynia and hyperalgesia, anticonvulsants such as gabapentin could be selected [7, 13]. In another study, Bruehl et al. suggested that CRPS patients can be grouped in a cold and warm phenotype [15]. The warm phenotype was characterised with a warm, red, oedematous and sweaty CRPS limb [15]. By contrast, the cold phenotype was associated with a CRPS limb that was cold, blue or pale, and also oedematous, although an oedematous limb was less common than in the warm CRPS group [15].

The categorisation of patients with CRPS in different phenotypes potentially reveals different underlying mechanisms of CRPS [7, 13, 15]. Increasing evidence strongly suggests that multiple mechanisms are responsible for the onset and/or maintenance of CRPS [7, 16-18]. Comparable with chronic pain management, substantial improvements in the management of CRPS can be possible if specific mechanisms are identified that drive different CRPS phenotypes $[7,19]$. Although some of the underlying mechanisms of CRPS can be the result of each other, the most prominent mechanism(s) should be targeted to make the most impact in the treatment of CRPS [7, 19].

In this review, we categorised the current and future pharmacotherapeutic options for CRPS into four groups based on the mechanisms they target: (1) inflammation; (2) peripheral and central sensitisation; (3) vasomotor disturbances; and (4) motor disturbances. These four mechanism-based indications for drug prescription are derived from different phenotypes and underlying mechanisms in CRPS [7, 13]. This review will discuss the actions of current and future pharmacotherapeutic options for CRPS in a mechanism-based manner. Drugs shown to be effective against the abovementioned four mechanisms are incorporated in this review.

This narrative review is based on PubMed and Google Scholar searches using the following search parameters (Medical Subject Headings and subheadings): CRPS, complex regional pain syndrome, reflex sympathetic dystrophy, causalgia, Sudeck's atrophy, physiopathology, aetiology, drug therapy, pain management, anaesthetics, analgesics, anti-inflammatory agents, botulinum toxins, muscle relaxants, cannabinoids, anticonvulsants, vasodilator agents, glucocorticoids, bisphosphonates, free radical scavengers, inflammation, nervous system diseases, movement disorders, dystonia, blood vessels and regional blood flow. Only articles written in English or Dutch were analysed. Of note, no distinction between CRPS type 1 (no demonstrable nerve lesion) and CRPS type II (demonstrable nerve lesion) will be made in this review because the management of the two CRPS types is not different.

\section{Inflammation}

An important underlying mechanism of CRPS is inflammation as a result of dysregulation of the immune system. In this section, we describe the hypothesised role of the adaptive and innate immune system, neurogenic inflammation, neuroinflammation, the hypothalamic-pituitary-adrenal (HPA) axis and autoantibodies in CRPS.

Several studies describe an overactive immune reaction to tissue damage in the acute phase of CRPS $[1,20]$. In this phase, signs of CRPS can usually be described as the classical signs of inflammation: pain (dolor), increased temperature (calor), swelling (tumour), redness (rubor) and loss of function (functio laesa) [21]. Although these symptoms belong to a normal physiological reaction to tissue damage - during the onset of CRPS—inflammation rather tends to persist instead of diminishing [20,22]. 
Both the innate and adaptive immune system contribute to the immune dysregulation in CRPS [23]. Regarding the innate immune system, activated keratinocytes, mast cells and glial cells elevate levels of proinflammatory cytokines that are detected in blister fluid, serum, plasma or cerebrospinal fluid of CRPS patients [20, 24-27]. These cytokines are linked to peripheral nociceptor activation and sensitisation, which can lead to hyperalgesia and pain [28]. In addition, increased levels of monocytes, and their resident tissue macrophages, may be important innate cellular components of inflammation in CRPS [29]. Evidence for contribution of the adaptive immune system is illustrated by altered T-cell activity and a higher prevalence of autoantibodies in CRPS patients [30-32].

Besides inflammation caused by immune dysregulation, peripheral neurogenic inflammation has also been suggested to play a role in CRPS [33]. Neurogenic inflammation is a phenomenon in which stimulated nociceptive $\mathrm{C}$-fibres release neuropeptides such as substance $\mathrm{P}$ and calcitonin gene-related peptide (CGRP) [34]. Serum CGRP and substance P levels in CRPS patients were higher than in healthy controls [25, 35]. The elevation of neuropeptides can explain some of the observed signs of CRPS as these neuropeptides cause vasodilation, protein extravasation and sweating, and influence local immune cells and neuronal structures [33, 34, 36, 37].

Another type of inflammation in CRPS is neuroinflammation [38, 39], a condition in which microglia are activated and release proinflammatory mediators that result in central and/or peripheral nervous system inflammation [40]. Microglia are the immune cells of the central nervous system (CNS) and have an important role in the coordination of the CNS immune reaction [41]. Neuroinflammation can be initiated by various types of trauma, and also by enhanced neuronal activity of primary afferent nerve fibres or higherorder neurons [40]. In CRPS, increased microglial activity in several brain regions has been shown in a positron emission tomography study by Jeon et al. [42]. Of importance is that neuroinflammation can contribute to the chronification of pain by facilitating central sensitisation [40]. The phenomenon of central sensitisation will be further discussed in Sect. 3.

Another system that interacts with inflammation in CRPS is the HPA axis [43]. The HPA axis can be activated by tissue damage and inflammatory cytokines [44]. These stimuli increase endogenous corticosteroid production that inhibits cytokine production and initiates a negative feedback loop on the hypothalamus and pituitary gland [44]. The HPA axis can thus be linked to the immune system and can suppress inflammation when activated [44]. Because there are signs of exaggerated inflammation in CRPS, the HPA axis in CRPS patients could be impaired [43, 45]. Park and Ahn detected decreased cortisol and reduced diurnal cortisol rhythms in
CRPS patients with frequent pain attacks, implying that the HPA axis did not function normally [43]. Since the HPA axis is a self-regulating negative feedback system, reduced cortisol levels are possibly a sign of decreased activity or impaired feedback sensitivity of the HPA axis [46].

Goebel and Blaes suggested that CRPS can be considered an autoantibody-mediated autoimmune syndrome that has a regionally confined course [47]. In autoimmune diseases, the innate immune system stimulates an immune response by the adaptive immune system against its own tissues [48]. In CRPS, Dirckx et al. showed that significantly more CRPS patients have positive antinuclear antibody test results than healthy blood bank donors [32]. In addition, immunoglobulin (Ig) G autoantibodies against surface antigens on autonomic neurons were demonstrated in CRPS patients but not in healthy controls $[49,50]$. In theory, by sensitising these neurons, autoantibodies may be able to produce the painful hypersensitivity observed in CRPS patients [51].

\subsection{Current Therapeutic Options}

\subsubsection{Corticosteroids}

Corticosteroids are key drugs for treating immunological diseases because of their anti-inflammatory and immunosuppressive effects [44]. In CRPS, corticosteroid treatment has been suggested for multiple purposes, such as inhibition of proinflammatory cytokines, influencing the HPA axis and diminishing increased T-cell activity [30, 43, 52]. Of note, clinical trials that studied corticosteroid treatment in poststroke CRPS patients are not discussed in this review. We believe that post-stroke CRPS is another phenotype with a different pathophysiology that may include disuse of the affected extremity.

One of the first randomised controlled trials (RCTs) studying corticosteroid treatment in CRPS patients $(n=23)$ was conducted by Christensen et al. in 1982 [53]. This study showed that the group with $10 \mathrm{mg}$ prednisone $3 \times$ day $^{-1}$ for a maximum of 12 weeks showed significantly more clinical improvement than the placebo group [53]. The clinical improvements were scored on pain, oedema, volar sweating and finger knitting ability [53]. With regard to the timing of corticosteroid prescription, Barbalinardo et al. showed that the efficacy of prednisolone is limited in CRPS patients with a syndrome duration of more than 3 months $(100 \mathrm{mg}$ day $^{-1}$ tapered by $25 \mathrm{mg}$ every 4 days to $0 \mathrm{mg}$ ) [54]. This underlines the significance of early recognition of CRPS to start corticosteroid treatment in the acute phase of CRPS. Several adverse effects are linked to corticosteroid use, such as malaise, stomach ache, depression, psychosis and weight gain $[52,54]$. Relatively long dosing regimens should be avoided because of the numerous contraindications for chronic corticosteroid use [55]. Further research should 
be conducted to form a standard dosing regimen and to ascertain possible predictors of response to corticosteroid treatment.

Besides oral administration of corticosteroids, intrathecal corticosteroids could be considered for the treatment of CRPS patients. Intrathecal administration of corticosteroids could be of interest because activation of spinal microglia has been suggested in neuropathic or nociplastic pain conditions [56, 57]. Munts et al. conducted an RCT to study the efficacy of a single intrathecal $60 \mathrm{mg}$ prednisolone bolus in CRPS patients [58]. Although this seemed promising, the study by Munts et al. was prematurely stopped as no difference was found on pain between the intrathecal prednisolone group and the placebo group [58]. This therapy was possibly not effective in the included patients with a mean CRPS duration of 5 years because activation of glial cells in the spinal cord is most likely to occur earlier in the course of the syndrome [58]. Regarding possible adverse effects, Munts et al. did not find any difference in adverse events between the intrathecal prednisolone and placebo group [58]. However, the safety of intrathecal corticosteroids is a matter of debate as Rijsdijk et al. reported meningeal inflammation after intrathecal corticosteroid administration in dogs [59].

\subsubsection{Bisphosphonates}

Bisphosphonates inhibit bone resorption by osteoclasts and are recommended for several bone-related pathologies, such as osteoporosis and Paget's disease. However, enhanced osteoclastic activity has never been shown in CRPS [60, 61]. Why bisphosphonates are effective in CRPS could be explained by multiple theories. These theories include interactions with the immune system, such as inhibition of macrophages and microglia and modulation of inflammatory mediators [62-64]. Furthermore, bisphosphonates regulate expression of nerve growth factor and reduce the acid-induced activation of primary afferent nociceptors [62, 63]. A combination of these mechanisms is most likely to result in pain relief in CRPS patients.

A systematic review by Chevreau et al. concluded that bisphosphonates achieve clinically relevant pain relief in CRPS patients [65]. That review included four RCTs using different treatment regimens: oral alendronate $40 \mathrm{mg}$ day $^{-1}$ for 8 weeks; a single $60 \mathrm{mg}$ intravenous dose of pamidronate; an intravenous dose of clodronate $300 \mathrm{mg} \mathrm{day}^{-1}$ for 10 days; and three infusions of $100 \mathrm{mg}$ neridronate over the course of 10 days [61, 66-68]. Pooled analysis of the included RCTs showed that pain scores of patients treated with bisphosphonates were significantly lower than the placebo group within 30-40 days $(n=181)$ and within the second and third month after administration $(n=67)$ [65]. With regard to treatment response, Varenna et al. reported three positive predictive factors for effective bisphosphonate treatment: a warm syndrome subtype; a short syndrome duration; and fracture as a predisposing event [69]. Currently, zoledronic acid is being studied in a phase III RCT in CRPS patients [70].

Despite the extensive research on bisphosphonate treatment for CRPS, the long-term effectiveness and the optimum frequency, duration and dosage of the treatment is still to be determined [65]. Bisphosphonates can be safely administered as administration does not cause serious adverse effects [65]. Mild adverse effects of bisphosphonates were mild fever, gastrointestinal intolerance, erythema and soreness at the infusion site, hypocalcaemia without clinical symptoms, and polyarthralgia [65].

\subsubsection{Free-Radical Scavengers}

For CRPS prophylaxis or treatment, free-radical scavengers such as dimethylsulfoxide (DMSO), $N$-acetylcysteine (NAC) and vitamin $\mathrm{C}$ can be prescribed. These drugs are antioxidants and scavenge oxygen-derived free radicals, which could trigger damage to membrane lipids and the microcirculation [71]. Microcirculatory disturbances and oxygenderived free radicals have been suggested to be associated with the initial inflammatory reaction in CRPS [72].

In an RCT by Zuurmond et al. $(n=32)$, topical DMSO $50 \%$ was applied on the CRPS extremity $5 \times$ day $^{-1}$ for 2 months [73]. In the group with DMSO, CRPS symptoms were significantly reduced compared with placebo [73]. Another RCT by Perez et al. assessed DMSO and NAC in 146 CRPS patients [74], and reported that DMSO $\left(5 \times\right.$ day $\left.^{-1}\right)$ and NAC $\left(600 \mathrm{mg} 3 \times\right.$ day $\left.^{-1}\right)$ resulted in equal reduction of CRPS symptoms at 1 year follow-up [74]. In the subgroup analysis, DMSO showed more beneficial results for warm CRPS, and NAC was significantly better for cold CRPS [74]. Reported adverse effects were skin reactions after DMSO application and stomach complaints after NAC administration [73, 74].

For the prevention of CRPS, administration of vitamin C (a water-soluble vitamin and strong antioxidant) has been studied [75]. With these antioxidant properties, vitamin $\mathrm{C}$ is capable of stabilising reactive oxygen-derived free radicals. This theory was further investigated in an RCT by Zollinger et al. in 123 patients with wrist fractures who were randomly allocated to $500 \mathrm{mg} \mathrm{day}^{-1}$ of vitamin $C$ or placebo for 50 days immediately after trauma [76]. The group of patients who received vitamin $\mathrm{C}$ was linked to a lower risk of developing CRPS [76]. A consecutive dose-finding RCT underlined $500 \mathrm{mg} \mathrm{day}^{-1}$ of vitamin $\mathrm{C}$ for 50 days as the most optimal dosage [77]. By contrast, the RCT by Ekrol et al. demonstrated no significant difference in the prevalence of CRPS after the same dosing regimen [78]. Several meta-analyses proved vitamin $\mathrm{C}$ as a prophylactic therapy for CRPS [79-81]. Considering vitamin $\mathrm{C}$ is harmless and 
cheap in the proposed dosage, both orthopaedic and CRPS guidelines recommend vitamin $\mathrm{C}$ as CRPS prophylaxis [11, $55,82,83]$.

\subsection{Future Therapeutic Options}

\subsubsection{Anti-Tumour Necrosis Factor Agents}

Several anti-tumour necrosis factor (TNF) agents are already used in inflammatory bowel diseases and rheumatoid arthritis. TNF $\alpha$ is a cytokine that stimulates the inflammatory cascade. In CRPS, TNF $\alpha$ levels are increased in both blister fluid and skin biopsies taken from affected extremities [20, 22, 84]. Therefore, anti-TNF agents (e.g. infliximab, adalimumab) may hold potential in the treatment of CRPS. Although anti-TNF therapy is generally well tolerated, serious adverse effects such as severe infections can occur [85]. Huygen et al. described the potential role of infliximab in the first case series with two CRPS patients [86]. A consecutive RCT by Dirckx et al. was designed to investigate infliximab therapy in CRPS patients 3-12 months after initial tissue damage [87]. Although this study was terminated before the required number of patients had been reached $(n=13)$, it showed a trend towards an effect of infliximab on the initially high TNF $\alpha$ levels in blister fluid [87]. Adalimumab was investigated by Eisenberg et al. in a case series of 10 CRPS patients [88], 3 of whom experienced a $\geq 2$-point reduction of pain score at follow-up of 6 months [88]. Unfortunately, no TNF $\alpha$ levels were measured in this study. Before anti-TNF treatment can be incorporated in CRPS guidelines, randomised studies are needed for higher quality of evidence.

\subsubsection{Thalidomide and Lenalidomide}

Thalidomide was re-introduced in the 1990s for the treatment of multiple myeloma after it was withdrawn from the market because it caused teratogenicity [89]. Lenalidomide, a derivative of thalidomide, was introduced to optimise the anti-inflammatory and antineoplastic characteristics of thalidomide with less prominent adverse events [89]. What is known about the mechanism of action of thalidomide and lenalidomide is that they have immunomodulatory properties and stimulate anti-inflammatory cytokines and inhibit the production of several proinflammatory cytokines, such as TNF $\alpha$ [89]. Several adverse effects are associated with thalidomide, such as deep vein thrombosis and peripheral neuropathy [89]. The most common serious adverse events of lenalidomide are myelosuppression, infections and thrombosis [89].

In an open-label study of thalidomide by Schwartzman et al., 42 therapy-refractory CRPS patients were prescribed thalidomide (at the start of therapy $200 \mathrm{mg} \mathrm{day}^{-1}$ and later titrated to $400 \mathrm{mg} \mathrm{day}^{-1}$ ) [90]. Thirty percent of patients reported pain reduction and the treatment effect was usually seen after 4-6 weeks [90]. Patients experienced more pain and oedema in the first weeks of treatment and reported mild adverse events such as rash, somnolence and constipation [90]. With regard to lenalidomide, a pilot-study by Schwartzman et al. $(n=40)$ reported a $\geq 2$-point NRS reduction in $29 \%$ of patients at week 12 and $52 \%$ of patients at 1 year [91]. In a consecutive RCT by Manning et al., the primary endpoint, defined as a $\geq 30 \%$ lower pain score compared with baseline, was not met as the placebo and lenalidomide group showed no differences in efficacy [92]. Lenalidomide was well tolerated and no major adverse events were reported [92]. Although lenalidomide cannot be recommended, Manning et al. indicated that a subgroup of CRPS patients with high plasma levels of inflammatory cytokines and their soluble receptors could be more prone to successful lenalidomide therapy [92].

\subsubsection{Plasma Exchange Therapy}

Plasma exchange therapy reduces factors that contribute to inflammation, such as proinflammatory cytokines and fibrinogen [93]. In the case series by Aradillas and colleagues, 30 of 33 CRPS patients experienced a pain reduction of $64 \%$ after plasma exchange therapy [93]. The plasma exchange therapy consisted of approximately seven plasma exchange transfusions in 3 weeks [93]. Only minor adverse events such as hypocalcaemia, hypoglycaemia and hypotension were reported, which were all treated with simple interventions [93]. The authors report that the achieved pain relief by plasma exchange therapy may be maintained by a weekly plasma exchange, intravenous immunoglobulin therapy or other immune-modulating drugs [93]. Of note, an RCT by Goebel et al. showed that intravenous immunoglobulin administration was not effective for pain reduction in CRPS patients with 1-5 years' syndrome duration [94].

\section{Peripheral and Central Sensitisation}

The CNS can protect the body from further harm after injury by, for instance, decreasing depolarisation thresholds and increasing firing after painful stimuli [16]. However, these protective mechanisms become pathological when they persist and contribute to neuroplasticity, central sensitisation and its resulting symptoms such as allodynia and hyperalgesia [16].

In the peripheral nervous system, degeneration of $\mathrm{C}$ and A delta fibres have been shown in the affected limbs of CRPS patients [95-97]. This small fibre neuropathy can lead to exaggerated sensory symptoms in CRPS [96]. In addition, coupling between the peripheral nervous system and 
the autonomic nervous system could develop in CRPS [98]. It is believed that catecholamines can produce pain locally by triggering adrenergic receptors on nociceptive fibres [98]. Upregulation of adrenergic receptors on nociceptive nerve fibres were shown by Drummond et al. in animal models after injury [99, 100]. Furthermore, hyperalgesia in humans could be produced after injection of the adrenoreceptor agonists norepinephrine and phenylephrine [101, 102]. Besides peripheral changes, central sensitisation that takes place in pain pathways of the brain and spinal cord is more likely to play a role in the continuous pain perception in CRPS.

Central sensitisation is the result of ongoing noxious input after tissue damage followed by an increased excitability and synaptic efficacy of neurons in nociceptive pathways [103]. In this process of enhanced pain signalling, increased levels of the excitatory amino acid glutamate activate the $N$-methyl-D-aspartate (NMDA) receptor [103]. Prolonged stimulation of this receptor causes the NMDA receptor to upregulate in the spinal cord and this enhances the efficacy of CNS neurotransmission [103, 104]. These maladaptive neuroplastic changes can amplify sensory input and lead to spontaneous pain, allodynia and hyperalgesia in CRPS patients [7, 103]. Central sensitisation symptoms can be examined by objectively derived parameters such as conditioned pain modulation and temporal summation [105, 106]. In addition, neuroinflammation can facilitate central sensitisation and therefore central sensitisation in CRPS can be caused by a combination of neuroinflammation and continuous sensory input $[39,40]$.

Central sensitisation can result in structural changes in the CNS. Signs of cortical reorganisation in CRPS have been found in both the primary somatosensory cortex and the motor cortex [107, 108]. For instance, in the somatosensory cortex, a reduced representation of the CRPS extremity and an increased representation of the unaffected extremity have been reported [107, 109]. In the study by Maihöfner et al., the reorganisation in the somatosensory cortex in CRPS patients was correlated to pain intensity [110]. Similarly, the extent of impaired endogenous pain inhibitory pathways was related to pain intensity $[111,112]$. Furthermore, two studies found disorganisation in grey and white matter in brain regions that correspond to pain perception and autonomic functions [113, 114]. Of note, autonomic symptoms such as temperature and sweating abnormalities in CRPS showed comparable patterns with stroke patients, implicating structural CNS changes in CRPS [115]. Fortunately, cortical reorganisation has been shown to be reversible with sensorimotor retuning of CRPS [116].

Another potential target for the treatment of CRPS is the endocannabinoid system (ECS), a central endogenous pain control pathway that can be targeted for inflammatory and neuropathic pain conditions [117]. Endogenous cannabinoids can be regarded as endogenous analgesics and have a crucial role in synaptic plasticity through inhibition of the release of $\gamma$-aminobutyric acid (GABA)-related, serotonergic, glutamatergic and dopaminergic neurotransmitters [118, 119]. Furthermore, endogenous cannabinoids can regulate microglial activity during inflammation [120]. In a CRPS model in rodents, $\mathrm{Xu}$ et al. showed that activation of the cannabinoid-2 receptor attenuates allodynia and neuroinflammatory responses [121]. Furthermore, Kaufmann et al. found enhanced plasma levels of the endocannabinoid anandamide in CRPS patients and suggested that the upregulation of peripheral anandamide levels seen in CRPS patients might be a protective mechanism to limit pain and inflammation [122].

\subsection{Current Therapeutic Options}

\subsubsection{Anticonvulsants}

Anticonvulsants, such as gabapentin and pregabalin, are used for CRPS because of the relatively good results in neuropathic pain conditions [123]. Gabapentin and pregabalin are thought to reduce neuronal hyperexcitability and have a complex synergy between increased GABA synthesis and binding to the $\alpha 2-\delta$ subunit of voltage-dependent calcium channels [124]. The latter action decreases the release of several neurotransmitters such as glutamate, norepinephrine and substance $P$ [124].

In an RCT by van de Vusse et al., 58 patients with a longstanding history of CRPS were randomised to two 3-week treatments with either gabapentin (up to $1800 \mathrm{mg}^{\text {day }}{ }^{-1}$ ) or placebo [125]. Patients reported a significantly reduced sensory deficit in the affected limb when using gabapentin versus placebo [125]. For 22 CRPS patients with a syndrome duration shorter than 3 months, the study by Tan et al. reported significantly lower pain scores after gabapentin use (up to $1800 \mathrm{mg} \mathrm{day}^{-1}$ ) [126]. Another RCT in paediatric CRPS patients compared the administration of gabapentin and amitriptyline and showed that both drugs equally decreased pain intensity [127].

A recently published review by Javed and Abdi on anticonvulsants and antidepressants for CRPS reported that gabapentinoids may result in significant clinical improvement [128]; however, there is insufficient evidence to incorporate them into regular clinical practice [128]. With regard to pregabalin, several paediatric case reports described effective results, but adult CRPS studies are lacking [128]. Commonly reported adverse effects of gabapentinoids were dizziness, somnolence and lethargy [125, 128].

\subsubsection{Ketamine (Intravenous, Topical, Oral)}

Various mechanisms of action have been reported for the beneficial effects of the NMDA receptor antagonist 
S-ketamine in CRPS [129]. The most prominent rationale to use S-ketamine in CRPS patients is that the activated and upregulated NMDA receptor in the spinal cord plays an important role in the wind-up phenomenon and central sensitisation [104, 130]. The analgesic effects of S-ketamine can most likely be attributed to prolonged NMDA receptor desensitisation, which counteract central sensitisation at spinal and supraspinal sites [104, 130, 131]. Other mechanisms of action of ketamine that may be beneficial to CRPS patients are anti-inflammatory properties [132], antidepressant properties [133] and alterations in the GABA/glutamate balance in the cerebral cortex [134].

In clinical practice, the intravenous route of administration of S-ketamine is most frequently used [129, 135, 139]. In the inpatient RCT by Sigtermans et al., 60 patients were randomised to placebo or a 4-day intravenous S-ketamine treatment [130]. The treatment was individually tailored based on adverse effects and pain reduction, with a mean S-ketamine dose of $22 \mathrm{mg} / \mathrm{h} \mathrm{[130].} \mathrm{Patients} \mathrm{reported} \mathrm{sig-}$ nificantly better improvement on pain scores until the 11th week of follow-up [130]. Another RCT by Schwartzman et al. randomised 26 CRPS patients in an outpatient setting to treatment with ketamine ( $4 \mathrm{~h}$ with a maximum of 25 $\mathrm{mg} / \mathrm{h}$ ) or placebo [136]. The group infused with ketamine reported a significant reduction in the sensory and affective components of pain in the McGill Pain Questionnaire until 3 months post-infusion [136].

A meta-analysis by Zhao et al. showed that S-ketamine infusions can provide clinically effective pain reduction for $<3$ months in CRPS patients [137]. Several adverse effects are associated with intravenous ketamine, such as psychotomimetic adverse effects and, in rare cases, hepatotoxicity [137, 138]. Unfortunately, no RCTs have been conducted that compare low and high dosing regimens. For S-ketamine infusions, there is insufficient international consensus and evidence to define a 'gold standard' treatment protocol [135, 139].

As intravenous ketamine administration can be considered invasive, other routes of ketamine administration have been proposed and studied, such as oral, topical, nebulised and intranasal ketamine. Of importance is the difference in bioavailability of the different routes of administration (bioavailability percentage): topical $<5 \%$; oral $10-20 \%$; sublingual 24-30\%; intranasal 25-50\%; nebulised $40-70 \%$ [135, $140,141]$.

Regarding topical ketamine, an RCT by Finch et al. studied the effects of $10 \%$ ketamine cream on sensory symptoms in 20 CRPS patients [142]. While topical ketamine did not result in pain relief, it did diminish allodynia and hyperalgesia in the affected limb [142]. The systemic effects of topical ketamine were ruled out because of undetectable plasma levels in blood [142], and the beneficial effects of topical ketamine were therefore suggested to be caused by local alterations in cutaneous nociceptors [142]. Considering the negligible chance of central adverse effects and that topical administration is non-invasive, topical ketamine therapy could be used as an add-on therapy for CRPS patients.

A review about ketamine in chronic pain management concluded that oral ketamine should not be used in routine practice because of its poor safety profile, poor bioavailability and lack of efficacy [143]. Although some studies reported beneficial results of oral ketamine in neuropathic conditions [144-146], no studies have been conducted that studied oral ketamine in CRPS patients.

\subsection{Future Therapeutic Options}

\subsubsection{Cannabinoids}

Recently, cannabinoids have gained interest in chronic pain. Although legislation and availability of cannabinoids are different across the world, they are being approved for pain management in an increasing number of countries [147]. Cannabinoids contain biologically active elements of cannabis, or synthetic compounds, which interact with the cannabinoid receptors and can modulate pain perception [148]. The generally well-known cannabinoids are the psychoactive $\Delta$ 9-tetrahydrocannabinol (THC) and the non-psychoactive cannabidiol (CBD). There are several different cannabinoid formulations for a wide variety of pain conditions [119]. The reported beneficial effects of cannabinoids on inflammation and pain make cannabinoids a promising therapeutic option for CRPS.

CRPS patients were included in three RCTs that studied cannabinoids [149-151]. Wilsey et al. showed that patients with neuropathic pain, of whom 22 of 38 were diagnosed with CRPS, who used low-dose (3.5\% THC) or high-dose (7\% THC) cannabis cigarettes for three 6-h sessions, experienced significant pain relief compared with placebo [150]. The same research group performed a study of vaporised cannabis (low-dose 1.3\% THC and medium-dose 3.5\% THC) and showed that both treatment groups experienced a significant ( $>30 \%$ ) pain reduction compared with the placebo group [149]. Psychoactive adverse effects were minimal and generally well-tolerated [149, 150]. However, cognitive performance could be affected when using high dosages of THC [150]. In the third RCT, Almog et al. showed that a novel selective-dose cannabis inhaler $(0.5$ or $1 \mathrm{mg}$ THC) produced a significantly better analgesic effect than placebo and lasted for $150 \mathrm{~min}$ [151]. Almog et al. mentioned that adverse events were mostly mild and temporary, and they further underlined the absence of consistent impairments in cognitive performance [151].

In chronic pain literature, cannabinoids have mostly been studied in neuropathic pain states. A reduction of neuropathic pain was reported in several meta-analyses [152-155]. 
A recent meta-analysis by Johal et al. reported moderate evidence to support cannabinoids to achieve pain relief in chronic non-cancer pain patients in 2 weeks, but reported insufficient evidence for the long term [156]. A recently published systematic review by Chang et al. about current medical cannabis guidelines concluded that only weak recommendations are available for cannabinoids for non-cancer pain, and they recommend that cannabinoids should be used as a third- or fourth-line therapy only [157].

\subsubsection{Ketamine (Intranasal, Sublingual and Nebulised)}

In 2019, the US FDA approved intranasal ketamine for the treatment of refractory depression [158]. Intranasal ketamine has been studied for chronic breakthrough pain and neuropathic pain $[159,160]$. Huge et al. included five CRPS patients in their RCT to compare $0.2 \mathrm{mg} / \mathrm{kg}$ with $0.4 \mathrm{mg} /$ $\mathrm{kg}$ intranasal S-ketamine in patients with neuropathic pain $(n=16)$ [160]. They reported a $31 \%$ reduction of pain score in the $0.2 \mathrm{mg} / \mathrm{kg}$ group versus a $38 \%$ reduction of pain score in the $0.4 \mathrm{mg} / \mathrm{kg}$ group [160]. Pain scores were significantly reduced for about $2-3 \mathrm{~h}$ [160]. The incidence of psychotomimetic adverse effects was significantly higher in the $0.4 \mathrm{mg} /$ $\mathrm{kg}$ dose group [160]. Furthermore, there could potentially be a role for nebulised and sublingual S-ketamine in pain management [140, 141]; however, evidence for these routes of administration is lacking in CRPS.

\subsubsection{Oral N-Methyl-D-Aspartate (NMDA) Receptor Antagonists}

Two new oral drugs interacting with the NMDA receptor are being developed. The first drug, BHV-5000, is a prodrug of its active metabolite lanicemine, a non-selective NMDA receptor antagonist studied for depression [161]. BHV-5000 is designed for neuropsychiatric disorders and is an NMDA antagonist that has the ability to uncouple from the NMDA receptor [162]. It is therefore less prone to create central dissociative adverse effects [162]. Because NMDA antagonists have shown beneficial results in CRPS patients, Bio-Haven Pharmaceuticals announced that BHV-5000 will be further investigated for neuropathic pain and other disorders involving NMDA receptor dysfunction such as CRPS [163, 164].

The second drug being developed is soticlestat, a positive allosteric modulator of the NMDA receptor with a novel mechanism of action by inhibiting the enzyme cholesterol 24-hydroxylase (CH24H) [165, 166]. This enzyme converts neuronal cholesterol to 24-hydroxycholesterol (24HC), a molecule predominantly expressed in the brain that leads to increased activation of the excitatory glutamate signalling pathway $[165,166]$. By inhibiting $\mathrm{CH} 24 \mathrm{H}$, NMDA receptor activation and glutamate production is decreased [165-167]. These mechanisms might be of interest because enhanced glutamatergic activity has been shown in CRPS [134, 168]. Furthermore, soticlestat may modulate glial function and inflammation by inhibiting $\mathrm{CH} 24 \mathrm{H}$ [167]. Soticlestat showed therapeutic potential in a phase Ib/IIb study as it reduced seizures in 18 patients with epileptic encephalopathies [167]. Soticlestat is currently being tested in a phase II study in CRPS by Takeda but the results have not yet been published [169].

\section{Vasomotor Disturbances}

Vasomotor disturbances in CRPS could be the result of both dysregulation in the autonomic nervous system and endothelial dysfunction $[98,170]$.

Regarding the autonomic nervous system, alterations in circulating catecholamines and/or super sensitivity to adrenoreceptors could play a role in the warm and cold presentation of CRPS [98, 170]. In the acute phase of CRPS, the affected limb is generally warm and red [15]. This initially warm limb usually develops into a cold and cyanosed limb in the chronic phase [15]. In the acute phase, a diminished autonomic vasoconstrictor activity, through a reduced release of catecholamines, could result in more cutaneous blood flow and a warm limb [171]. This is supported by studies by Drummond et al. that showed low levels of noradrenaline in venous blood of the affected limb in the acute phase of CRPS [172, 173]. In addition, proinflammatory cytokines could trigger the upregulation of adrenoreceptors and may increase the binding affinity of catecholamines to adrenoreceptors $[174,175]$. In the chronic phase, this increased binding affinity of catecholamines could cause a reduction in blood flow, with decreased tissue saturation and acidosis, which can cause ischaemic pain and the typical cold and cyanosed limb presentation [98, 170, 176].

The described hypo-oxygenation and possible acidosis in the CRPS extremity [176] may also be caused by proinflammatory cytokines that can induce endothelial dysfunction [170]. Endothelial function plays a pivotal role in microcirculation by the release of vasodilators (nitric oxide [NO], bradykinin, prostacyclin) and vasoconstrictors such as endothelin-1 (ET-1) [170]. Groeneweg et al. showed an increased level of ET-1 and a decreased level of NO in blister fluid of the affected extremity of patients with cold CRPS [177]. This local imbalance of NO and ET-1 may result in microcirculatory vasoconstriction and could result in impaired tissue oxygenation and ischaemic pain [170, 176, 177]. 


\subsection{Current Therapeutic Options}

\subsubsection{Vasodilators}

Several vasodilators can be considered in cold CRPS patients with autonomic disturbances to regulate the microcirculatory symptoms of the affected limb [170]. For instance, the calcium entry blocker nifedipine is a vasodilator that relaxes smooth muscles and antagonises the effects of norepinephrine on arterial and venous smooth muscles [178]. Prough et al. reported that 7 of 13 CRPS patients (54\%) had complete relief of symptoms after nifedipine administration. A majority of the patients had vasomotor dysregulation proven by cold stress testing [178].

Another vasodilator is phenoxybenzamine, an $\alpha$-adrenergic receptor antagonist that blocks both the $\alpha$-adrenergic receptors that regulate vasoconstriction and the $\alpha$-adrenergic receptors on nociceptive nerve fibres that are able to produce cathecholamine-induced pain [179]. Phenoxybenzamine and nifedipine were studied in a retrospective study by Muizelaar et al. in 59 CRPS patients [180]. Patients were administered oral phenoxybenzamine to a maximum of $120 \mathrm{mg} \mathrm{day}^{-1}$ and nifedipine to a maximum of $60 \mathrm{mg} \mathrm{day}^{-1}$ for 2-3 months [180]. The success rate of these drugs in early-stage CRPS patients with a syndrome duration of 1-3 months was higher (92\%) than chronicstage CRPS patients with a syndrome duration $>7$ months (40\%) [180]. The most reported adverse effects caused by nifedipine administration were headaches $[178,180]$, while the adverse effects of phenoxybenzamine were dizziness, nausea, diarrhoea and impotence of male patients [180]. More than $20 \%$ of patients stopped the therapy due to these adverse effects [180].

The phosphodiesterase- 5 inhibitor tadalafil can be considered in patients with endothelial dysfunction [170]. Tadalafil leads to a higher level of intracellular cyclic guanosine monophosphate (cGMP) and results in relaxation of smooth muscle cells and vasodilatation [170]. Tadalafil is registered and is used for the treatment of erectile dysfunction and pulmonary hypertension [181, 182]. In CRPS, tadalafil may be of interest in the subgroup of CRPS patients with a predominantly cold CRPS extremity due to endothelial dysfunction [170]. For this reason, Groeneweg et al. studied tadalafil 20 mg day ${ }^{-1}$ for 3 months versus placebo in 24 CRPS patients [183]. While the temperature asymmetry measured by thermography was not significantly reduced, most patients in the tadalafil group reported that the affected extremity felt warmer [183], which could be the result of restored microcirculation in the affected extremity. In addition, the pain scores were significantly lower after tadalafil administration, which could be the result of a reduction of local ischaemic pain $[170,176]$. Groeneweg et al. reported no severe adverse events after tadalafil administration [183].

\subsection{Future Therapeutic Options}

\subsubsection{Topical Treatments}

New topical treatments have recently been studied that target microvascular dysfunction in CRPS. First, Drummond et al. studied the application of prazosin cream, an $\alpha 1$-adrenoceptor antagonist, and showed that prazosin cream inhibited allodynia and hyperalgesia in the affected CRPS extremity without adverse effects [184]. Second, Russo and Santarelli developed a topical cream with a combination of several drugs consisting of ketamine $10 \%$, pentoxifylline $6 \%$, clonidine $0.2 \%$, and dimethylsulfoxide $6-10 \%$. In that study, 9/13 (69\%) CRPS patients reported pain reduction and none experienced any adverse effects [185]. Finally, Maihöfner et al. studied topical ambroxol $20 \%$ in a case series of eight CRPS patients with a syndrome duration of $<1$ year [186]. Ambroxol is a secrotolytic cream that blocks sodium channels [186]. Besides the strong local anaesthetic effect, ambroxol had antioxidative, anti-inflammatory and vasomotor properties [186]. Sensory and vasomotor signs improved in most cases after application of this cream and no adverse events were reported [186].

\section{Motor Disturbances}

Approximately 25\% of CRPS patients suffer from movement disorders such as dystonia, bradykinesia, myoclonus and tremor [187]. A combination of factors contributes to movement disorders in CRPS. First, Maihöfner et al. showed reorganisation of central motor circuits with increased activation of the primary motor cortex [188]. Second, changes in the basal ganglia have been demonstrated [189]. Third, an imbalance in flexor and extensor motor stimulation in the spinal cord in favour of the flexor muscles has been shown [190]. Fourth, a loss of central inhibitory circuits could trigger movement disorders and could be the result of diminished GABA-related inhibition and/or increased NMDArelated excitation [187, 191, 192]. Lastly, motor symptoms can also develop when avoiding pain by underuse or disuse of the affected extremity [193].

\subsection{Current Therapeutic Options}

\subsubsection{Baclofen}

Baclofen administration might be beneficial to relieve spasms, clonus and dystonia in CRPS patients. Baclofen stimulates the GABA receptor on primary afferent fibres and depresses their sensory transmission to the spinal cord [194]. The muscle relaxant characteristics of baclofen are caused by selective inhibition of excitatory potentials in 
motor neurons that result in lower reflex activity in the spinal cord [194].

Several studies reported successful treatment of dystonia in CRPS patients by using continuous intrathecal administration of baclofen. Intrathecal baclofen therapy could improve dystonia, disability and pain scores in a subgroup of CRPS patients [195-197]. However, van Rijn et al. reported a high percentage of adverse events after intrathecal baclofen treatment, including post-dural puncture headache, failure of drug delivery and neuropsychiatric symptoms as a result of the withdrawal of baclofen [196]. A review by Delhaas and Huygen on the complications associated with intrathecal baclofen treatment concluded that patients have to meet strict conditions and undergo surgery in specialised centres, as withdrawal or overdosing of baclofen can result in fatal complications [198].

Given the invasiveness and high risk of serious adverse events after intrathecal baclofen administration, it seems justified to administer oral baclofen first to treat motor symptoms [7]. Some studies reported that oral baclofen could diminish dystonia symptoms in CRPS [199, 200], however oral baclofen has disadvantages, such as lower penetration to the spinal cord due to limited passage through the blood-brain barrier and dose-limiting sedative properties [201].

\subsection{Future Therapeutic Options}

\subsubsection{Botulinum Toxin A}

Botulinum toxin A can be prescribed for both movement disorders such as spasticity and dystonia and for neuropathic pain conditions [202]. The effect of botulinum toxin A in movement disorders is achieved through its relaxing effect on skeletal muscles by inhibiting acetylcholine release at neuromuscular junctions [202, 203]. Botulinum toxin A also has beneficial effects through inhibition of neuropeptide release such as substance $\mathrm{P}$ and CGRP, which results in less neurogenic inflammation [202, 203].

In CRPS, relatively small studies with subcutaneous injections or intramuscular injections of botulinum toxin $\mathrm{A}$ reported beneficial effects on pain and motor function [204, 205]. Intramuscular botulinum toxin A injections of, in total, 100 units were studied in 37 CRPS patients with spasticity or dystonia in the neck or upper limb girdle muscles [204]. The average pain score reduced by almost 4 points $(43 \%)$ after botulinum toxin A treatment [204]. Besides one patient developing transient neck drop after injection, no other serious adverse events were reported [204]. Regarding motor effects, Schilder et al. suggested reserving botulinum toxin A for patients who have muscular hyperactivity [203]. Muscular hyperactivity can be diagnosed with electromyography and may be used to select responders to botulinum toxin A [203].

The effect of subcutaneous injections with botulinum toxin A was studied by Lessard et al. in 20 CRPS patients [205]. The patients showed a 2-point pain score reduction after injection of a maximum of 100 units of botulinum toxin A [205]. By contrast, an RCT by Safarpour et al. showed no improvements on allodynia after intradermal/subcutaneous injections with botulinum toxin A (mean dose 80 units) [206]. The study included 14 CRPS patients but was prematurely stopped because of intolerance to the injections [206].

\section{Expert Opinion}

CRPS is a multimechanism syndrome and the signs and symptoms cannot usually be explained by only one underlying mechanism. In this review, the current and future pharmacotherapeutic options for CRPS that act on inflammation, peripheral and central sensitisation, vasomotor disturbances and motor disturbances are discussed. The prescribed drugs for CRPS should target the most prominent mechanism(s) determined by history taking and physical examination. Overall, the evidence for most pharmacotherapeutic options for CRPS is of limited quality. Unfortunately, no big RCTs have been conducted. Most studies evaluating drugs used for CRPS have either been restricted by their small sample sizes or are uncontrolled studies. An overview of the conducted RCTs in CRPS and the pharmacotherapeutic mechanism-based options in CRPS are presented in Table 1 and Fig. 1, respectively.

Our research group hypothesises that inflammation after tissue damage is the underlying mechanism that initiates CRPS. Damage caused by exaggerated inflammation can result in all other non-inflammatory mechanisms that contribute to the different CRPS phenotypes. Figure 2 illustrates the central role of inflammation that could result in central sensitisation and vasomotor and motor disturbances in CRPS [207]. We believe that inflammation, an afferent mechanism (transit signals to the CNS), can cause endothelial dysfunction (disbalance NO/ET-1), small fibre neuropathy and an increased adrenergic receptor density. An inflammatory cascade contributes to the release of cytokines (interleukin [IL]-6, TNF $\alpha$ ) and neuropeptides (CGRP and substance P). The release of CGRP and substance $P$ from peripheral nerve fibres result in neurogenic inflammation. When inflammation persists, microglia in the spinal cord and brain can be activated and can initiate neuroinflammation. Neuroinflammation and continuous sensory input drive central sensitisation. Efferent mechanisms (transit signals away from the CNS) include central sensitisation through NMDA upregulation, GABA-mediated motor disturbances and alterations in the activity of the autonomic nervous system. Eventually, 
Table 1 Evidence of available randomised controlled trials on pharmacotherapeutic options for complex regional pain syndrome

\begin{tabular}{|c|c|}
\hline Drug & Evidence of available RCTs \\
\hline \multicolumn{2}{|l|}{ Inflammation } \\
\hline Corticosteroids & $\begin{array}{l}\text { Oral corticosteroids may result in clinical improvement of CRPS [53] } \\
\text { Intrathecal corticosteroids were not effective in CRPS [58] }\end{array}$ \\
\hline Bisphosphonates & Bisphosphonates can result in clinically relevant pain relief $[61,66-68]$ \\
\hline Free radical scavengers & $\begin{array}{l}\text { Vitamin C: For the prevention of CRPS, vitamin C } 500 \mathrm{mg} \text { for } 50 \text { days immediately after trauma can be } \\
\text { administered }[76,77] \\
\text { DMSO: } 50 \% \text { DMSO }\left(5 \times \text { day }^{-1}\right) \text { for } 3 \text { months can be applied in patients with prominent inflammatory } \\
\text { symptoms (warm CRPS) and a CRPS duration of }<1 \text { year }[73,74] \\
\text { NAC: NAC prescription }\left(600 \mathrm{mg} 3 \times \text { day }^{-1}\right) \text { for } 3 \text { months in patients with cold CRPS [74] }\end{array}$ \\
\hline $\begin{array}{l}\text { Immunomodulatory drugs (tha- } \\
\text { lidomide, lenalidomide, anti-TNF } \\
\text { agents) }\end{array}$ & $\begin{array}{l}\text { Infliximab: A trend was found toward an effect on infliximab on the initially high TNF } \alpha \text { concentration in } \\
\text { patients with neuroinflammation in acute CRPS. This study was underpowered to draw definite conclu- } \\
\text { sions [87] }\end{array}$ \\
\hline Plasma exchange therapy & No RCTs \\
\hline \multicolumn{2}{|l|}{ Peripheral and central sensitisation } \\
\hline Ketamine & $\begin{array}{l}\text { Intravenous ketamine can provide clinically effective pain relief in the short term, up to } 3 \text { months post- } \\
\text { infusion }[130,136] \\
\text { Topical ketamine can be used to reduce allodynia [142] }\end{array}$ \\
\hline Anticonvulsants & $\begin{array}{l}\text { Gabapentin can reduce sensory dysfunction such as hypoesthesia in the affected limb [125] } \\
\text { Gabapentin and amitriptyline can equally decrease pain intensity in paediatric CRPS patients [127] }\end{array}$ \\
\hline Cannabinoids & Cannabis-based medicines could be an effective treatment for CRPS patients [149-151] \\
\hline Oral NMDA antagonists & No RCTs \\
\hline \multicolumn{2}{|l|}{ Vasomotor disturbances } \\
\hline Calcium channel blocker & No RCTs \\
\hline$\alpha$-Adrenergic blocker & No RCTs \\
\hline Phosphodiesterase-5 inhibitor & Tadalafil can be used to reduce pain in the context of a trial for patients with cold CRPS [183] \\
\hline \multicolumn{2}{|l|}{ Motor disturbances } \\
\hline Baclofen & $\begin{array}{l}\text { Intrathecal baclofen can be considered for therapy-refractory CRPS patients to improve dystonia [195, } \\
\text { 196] }\end{array}$ \\
\hline Botulinum toxin A & $\begin{array}{l}\text { Intradermal and subcutaneous injections of botulinum toxin A failed to improve pain and allodynia and } \\
\text { was poorly tolerated in CRPS patients [206] }\end{array}$ \\
\hline
\end{tabular}

$R C T$ randomised controlled trials, CRPS complex regional pain syndrome, DMSO dimethylsulfoxide, $N A C N$-acetylcysteine, $N M D A N$-methylD-aspartate, $T N F$ tumour necrosis factor

maladaptive neuroplasticity in the CNS can result in cortical reorganisation, which can have effects on pain perception and autonomic and motor function.

The mechanisms discussed above are used in our suggested CRPS treatment algorithm (see Fig. 3) [7]. In our tertiary referral centre, all CRPS patients are advised to start active physiotherapy. Physiotherapy, physical rehabilitation and physical agent modalities can result in pain relief and better function in CRPS patients [11, 82, 208]. Medication can be prescribed in addition to active physiotherapy. During history taking and physical examination, we differentiate between CRPS phenotypes using the most prominent signs and symptoms. In addition, we assess the serum level of soluble IL-2 receptor (sIL-2R), which is a surrogate marker for T-cell activation [30]. Although serum sIL-2R may not be useful in establishing the diagnosis of CRPS [209], we use the biomarker for monitoring the activity of (T-cellmediated) inflammation in CRPS. CRPS patients with an inflammatory phenotype and/or an elevated serum sIL-2R are treated with anti-inflammatory or immunomodulating drugs. In the acute inflammatory phase, we prescribe topical $50 \%$ DMSO for 3 months. If inflammation in CRPS persists, bisphosphonates treatment or a short-term treatment with corticosteroids can be considered. In select cases only, after consultation with an immunologist, CRPS patients can be prescribed anti-TNF or thalidomide treatment.

In CRPS patients with signs of peripheral and central sensitisation (e.g. allodynia and hyperalgesia), anticonvulsants such as gabapentin are prescribed. Subsequently, intravenous ketamine can be considered to weaken the wind-up phenomenon and prevent maladaptive neuroplasticity. In our clinic, clinical signs of central sensitisation can be supported by quantitative sensory testing. For evidently cold CRPS, calcium channel blockers and phosphodiesterase- 5 inhibitors can be administered. We start stepwise, first with nifedipine and then if vasomotor signs and symptoms persist, 


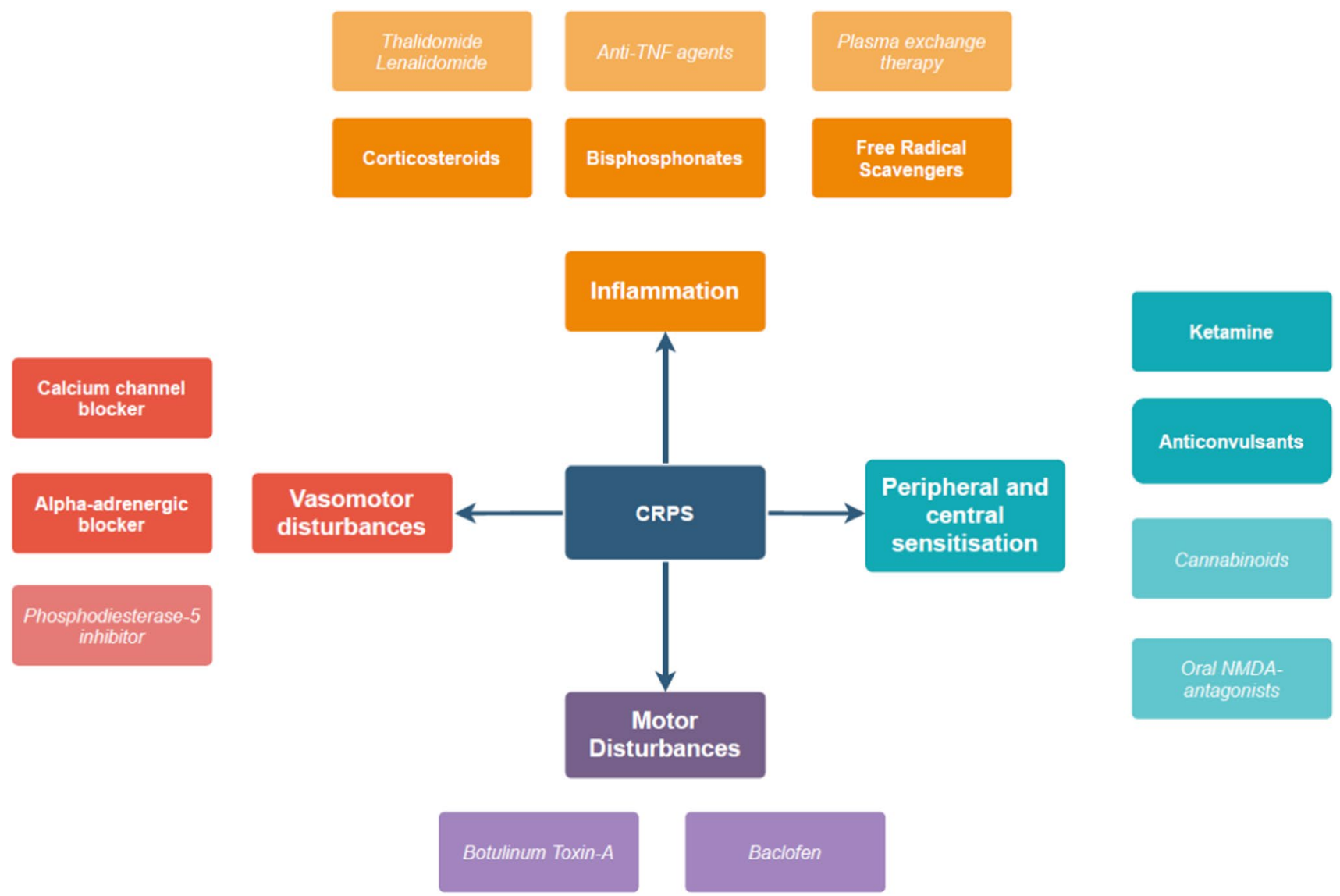

Fig. 1 Overview of mechanism-based pharmacotherapeutic options in complex regional pain syndrome. Experimental therapies are light-coloured and italicised. CRPS complex regional pain syndrome, $N M D A N$-methyl-D-aspartate, $T N F$ tumour necrosis factor

tadalafil can be considered. We have limited experience with $\alpha$-adrenoreceptor blockers. To objectify temperature asymmetry, thermography can be used. In patients with prominent motor disturbances, muscle relaxants or spasmolytics can be prescribed. We use oral baclofen to treat severe dystonia, and although we use intrathecal baclofen to treat spasticity for other conditions, we refrain from using intrathecal baclofen treatment for CRPS due to the high risks of technical problems. If no satisfactory results are reached after several mechanism-based drug administrations, invasive treatment such as neuromodulation can be considered.

Unfortunately, the optimal timeframe for the prescription of most pharmacotherapeutic options in CRPS have not been defined (i.e., in the acute or chronic phase of CRPS). Most drugs in this review are only administered in therapyrefractory CRPS patients with a relatively long syndrome duration; however, some drugs should be considered in an earlier phase of CRPS. For instance, the contribution of inflammatory mechanisms to CRPS is most likely to be most prominent in the early phase of this syndrome [210]. Therefore, anti-inflammatory or immunomodulating drugs could be considered in the acute phase of CRPS to prevent further damage by inflammation. Furthermore, it is mostly unknown whether the selected mechanism-based treatment is effective because the outcome measures of clinical trials do not usually cover objective parameters of the CRPS mechanisms, i.e. inflammation, central sensitisation and vasomotor and motor disturbances. We believe that besides pain scores as outcome measures, other parameters such as quantitative sensory testing, laboratory biomarkers and imaging techniques should give more insight into the effect of the drugs on the targeted mechanism(s).

Phenotyping of CRPS patients after history taking and physical examination could be helpful in selecting specific therapies for CRPS mechanisms. Furthermore, reliable objective diagnostic test(s) would be welcome to supplement the clinical diagnosis of CRPS, and these tests could help to differentiate between different CRPS mechanisms [39, 211]. Several biomarkers for CRPS have been studied but they first need to be validated and correlated to CRPS symptoms and signs. Hopefully, these biomarkers will prevent diagnostic delay and help an early mechanism-based therapy selection. Possible biomarkers for CRPS are discussed extensively in the reviews by Bharwani et al. and Birklein et al. [39, 211]. 


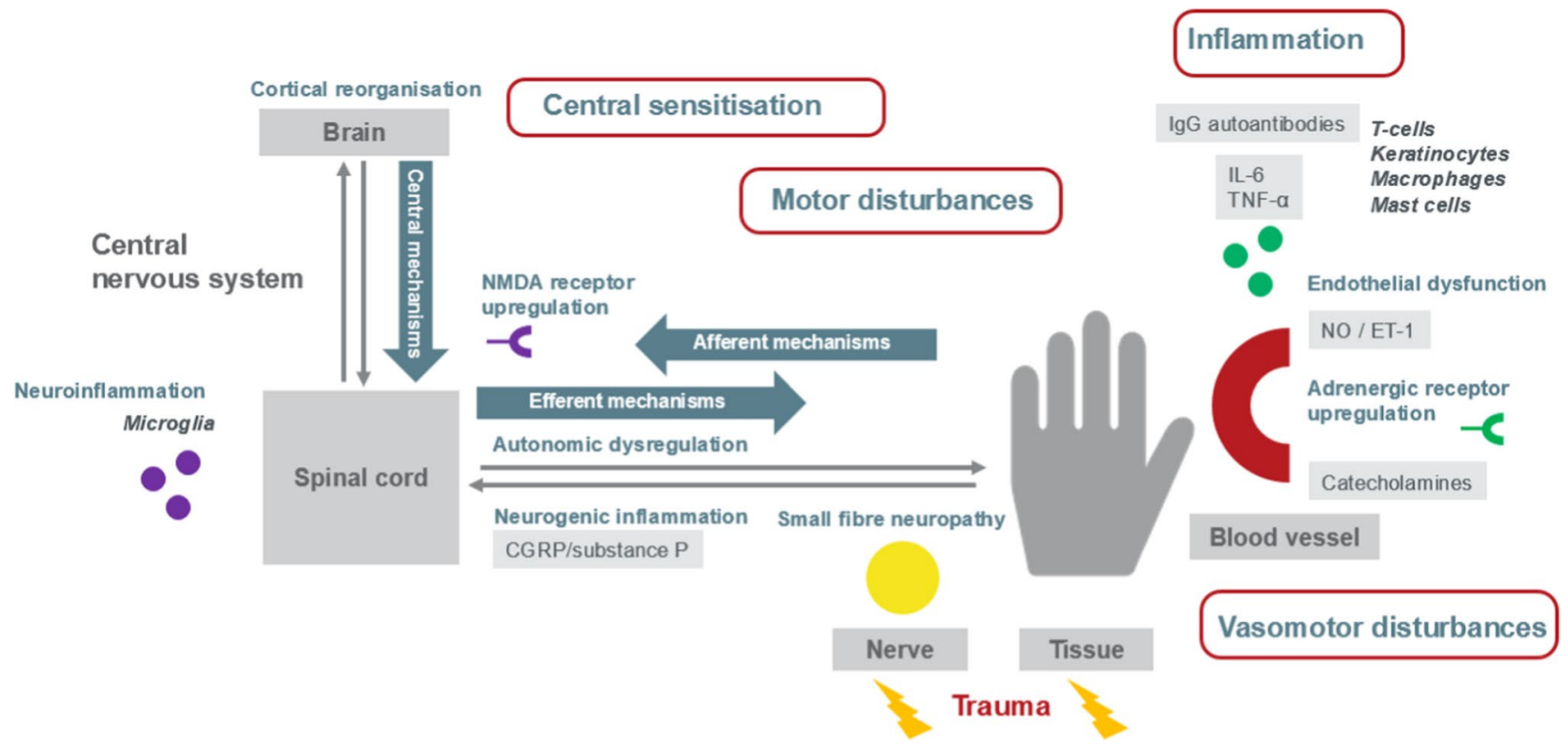

Fig. 2 Overview of afferent, efferent and central mechanisms that contribute to complex regional pain syndrome. Different afferent (transit signals to the central nervous system), efferent (transit signals away from the central nervous system) and central mechanisms play a role in CRPS. Afferent mechanisms are inflammation, small fibre neuropathy and vasomotor dysfunction through endothelial dysfunction and adrenergic receptor upregulation; efferent mechanisms are autonomic dysregulation, central sensitisation through NMDA recep-

In a multimechanism syndrome, a multidisciplinary approach including pharmacotherapy, physiotherapy, psychological intervention and invasive treatments is needed. However, in clinical CRPS trials, patients usually receive a single therapy only. Because CRPS is a multimechanism syndrome and targeting only a single mechanism might not be sufficient, it is extremely difficult to achieve positive results in trials that study monotherapies. Therefore, studies that study monotherapies in CRPS must be interpreted with caution, as these monotherapies in a multimechanism syndrome may only have limited beneficial results. Unfortunately, multitherapy solutions make evaluation of the selected therapies in a research setting very challenging; however, a multitherapy strategy may be mandatory to offer the best management strategy for CRPS patients.

As research continues to reveal more about the mechanisms that contribute to CRPS, diagnostic tools to differentiate between CRPS mechanisms will keep on evolving. If pain physicians are able to determine the most prominent mechanisms by objective criteria, then the results of mechanism-based research on drugs will be more easily implemented in clinical practice. CRPS expert centres should combine their efforts to develop international multicentre trials to study existing and promising drugs that target specific CRPS mechanisms. This raises the hope for an tor upregulation and GABA-mediated motor disturbances; and central mechanisms are neuroinflammation and cortical reorganisation. Derived from the Handbook of Pain Medicine [207]. CGRP calcitonin gene-related peptide, CRPS complex regional pain syndrome, ET-1 endothelin-1, GABA $\gamma$-aminobutyric acid, I $g$ immunoglobulin, $I L$ interleukin, $N O$ nitric oxide, NMDA $N$-methyl-D-aspartate, TNF tumour necrosis factor

internationally more mechanism-based treatment approach in CRPS.

\section{Conclusion}

The current and future pharmacotherapeutic options for CRPS can be categorised into groups that act on inflammation, peripheral and central sensitisation, vasomotor disturbances, and motor disturbances. The drugs should target the most prominent mechanism(s) determined by history taking and physical examination. Unfortunately, most studies evaluating drugs used for CRPS have either been restricted by their small sample sizes or are uncontrolled studies. In addition, only a few trials have used a mechanism-based approach instead of a symptom-based approach. In the future, objective diagnostic tests, supplementary to the clinical diagnostic CRPS criteria, could help differentiate between different CRPS mechanisms and support the selection of mechanism-based drugs. Furthermore, this mechanism-based approach could aid in patient selection for clinical trials on (emerging) drugs for CRPS. As research continues to reveal more about the pathophysiology of CRPS, pharmacotherapeutic options for CRPS will 
New IASP CRPS Criteria'

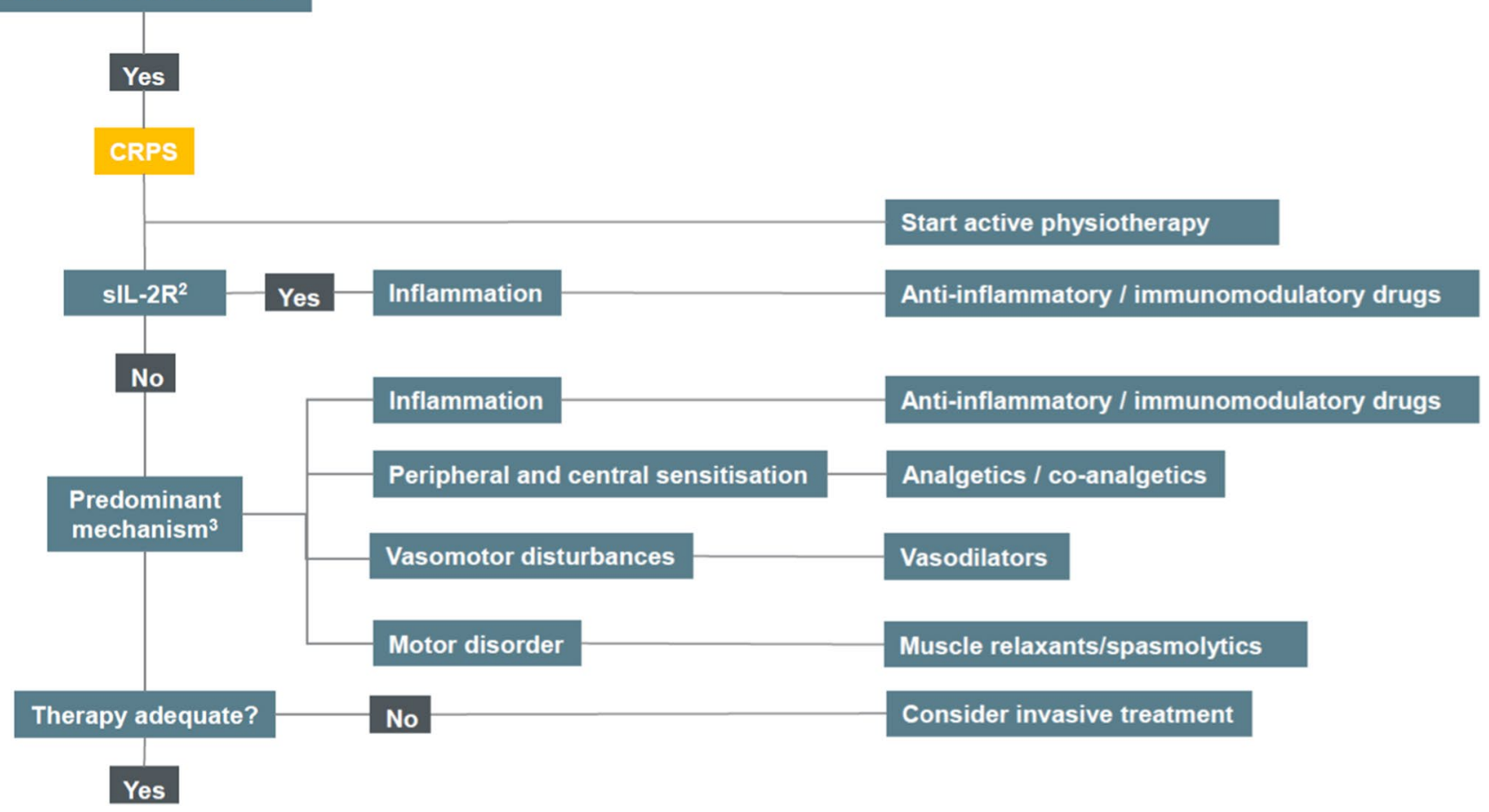

Fig. 3 Suggested treatment algorithm for CRPS. Derived from Bharwani et al. [7]. ${ }^{1}$ New IASP clinical diagnostic criteria for CRPS [8]. ${ }^{2}$ The sIL-2R is a surrogate marker for T-cell activation [30]. Although serum sIL-2R may not be useful in establishing the diagnosis of CRPS [209], we use the biomarker for monitoring the activ-

be more specific and will be tailored individually to CRPS patients in a mechanism-based manner.

\section{Declarations}

Funding No funding was received to assist with the preparation of this manuscript.

Conflicts of interest Frank J.P.M. Huygen reports personal fees from Abbott; grants and personal fees from Saluda; and personal fees from Boston Scientific, Grunenthal, and Pfizer outside the submitted work. Thomas J.P. Mangnus, Krishna D. Bharwani, and Maaike Dirckx report no other conflicts of interest that are relevant to the contents of this article.

Availability of data and material Not applicable.

Code availability Not applicable.

Ethics approval Not applicable.

Consent Not applicable.

Authors' contributions TJPM drafted the manuscript. KDB, MD and FJPMH co-authored this manuscript. All authors critically edited, read, and approved the final manuscript. ity of (T-cell mediated) inflammation in CRPS. ${ }^{3}$ Predominant CRPS mechanisms at history taking and physical examination. CRPS complex regional pain syndrome, IASP International Association for the Study of Pain, $s I L-2 R$ soluble interleukin-2 receptor

Open Access This article is licensed under a Creative Commons Attribution-NonCommercial 4.0 International License, which permits any non-commercial use, sharing, adaptation, distribution and reproduction in any medium or format, as long as you give appropriate credit to the original author(s) and the source, provide a link to the Creative Commons licence, and indicate if changes were made. The images or other third party material in this article are included in the article's Creative Commons licence, unless indicated otherwise in a credit line to the material. If material is not included in the article's Creative Commons licence and your intended use is not permitted by statutory regulation or exceeds the permitted use, you will need to obtain permission directly from the copyright holder. To view a copy of this licence, visit http://creativecommons.org/licenses/by-nc/4.0/.

\section{References}

1. Veldman PH, Reynen HM, Arntz IE, Goris RJ. Signs and symptoms of reflex sympathetic dystrophy: prospective study of 829 patients. Lancet. 1993;342(8878):1012-6. https://doi.org/10. 1016/0140-6736(93)92877-v.

2. de Rooij AM, Perez RSGM, Huygen FJ, Eijs FV, Kleef MV, Bauer MCR, et al. Spontaneous onset of complex regional pain syndrome. Eur J Pain. 2010;14(5):510-3. https://doi.org/10. 1016/j.ejpain.2009.08.007.

3. de Mos M, de Bruijn AG, Huygen FJ, Dieleman JP, Stricker $\mathrm{BH}$, Sturkenboom MC. The incidence of complex regional pain 
syndrome: a population-based study. Pain. 2007;129(1-2):12-20. https://doi.org/10.1016/j.pain.2006.09.008.

4. Ott S, Maihöfner C. Signs and symptoms in 1,043 patients with complex regional pain syndrome. J Pain. 2018;19(6):599-611. https://doi.org/10.1016/j.jpain.2018.01.004

5. Sandroni P, Benrud-Larson LM, McClelland RL, Low PA. Complex regional pain syndrome type I: incidence and prevalence in Olmsted county, a population-based study. Pain. 2003;103(12):199-207. https://doi.org/10.1016/s0304-3959(03)00065-4.

6. de Mos M, Sturkenboom MC, Huygen FJ. Current understandings on complex regional pain syndrome. Pain Pract. 2009;9(2):86-99. https://doi.org/10.1111/j.1533-2500.2009. 00262.x.

7. Bharwani KD, Dirckx M, Huygen FJPM. Complex regional pain syndrome: diagnosis and treatment. BJA Educ. 2017;17(8):2628. https://doi.org/10.1093/bjaed/mkx007.

8. Harden RN, Bruehl S, Perez RSGM, Birklein F, Marinus J, Maihofner C, et al. Validation of proposed diagnostic criteria (the "Budapest Criteria") for complex regional pain syndrome. Pain. 2010;150(2):268-74. https://doi.org/10.1016/j.pain.2010. 04.030.

9. Atkins RM, Duckworth T, Kanis JA. Algodystrophy following Colles' fracture. J Hand Surg Am. 1989;14(2):161-4. https://doi. org/10.1016/0266-7681_89_90118-6.

10. Goebel A, Birklein F, Brunner F, Clark JD, Gierthmuhlen J, Harden N, et al. The Valencia consensus-based adaptation of the IASP complex regional pain syndrome diagnostic criteria. Pain. 2021;162(9):2346-8. https://doi.org/10.1097/j.pain.00000 00000002245.

11. Perez R, Geertzen JHB, Dijkstra PU, Dirckx M, Van Eijs F, Frölke JP. Updated guidelines complex regional pain syndrome type 1. Utrecht: The Dutch Pain Society; 2014.

12. Iolascon G, Moretti A. Pharmacotherapeutic options for complex regional pain syndrome. Expert Opin Pharmacother. 2019;20(11):1377-86. https://doi.org/10.1080/14656566.2019. 1612367.

13. Bruehl S, Harden RN, Galer BS, Saltz S, Backonja M, Stanton-Hicks M. Complex regional pain syndrome: are there distinct subtypes and sequential stages of the syndrome? Pain. 2002;95(1-2):119-24. https://doi.org/10.1016/S0304-3959(01) 00387-6.

14. Gibbons JJ, Wilson PR. RSD score: criteria for the diagnosis of reflex sympathetic dystrophy and causalgia. Clin J Pain. 1992;8(3):260-3.

15. Bruehl S, Maihofner C, Stanton-Hicks M, Perez RS, Vatine JJ, Brunner F, et al. Complex regional pain syndrome: evidence for warm and cold subtypes in a large prospective clinical sample. Pain. 2016;157(8):1674-81. https://doi.org/10.1097/j.pain.00000 00000000569.

16. Bruehl S. Complex regional pain syndrome. BMJ. 2015;351: h2730. https://doi.org/10.1136/bmj.h2730.

17. Birklein F, Schlereth T. Complex regional pain syndrome-significant progress in understanding. Pain. 2015;156(Suppl 1):S94103. https://doi.org/10.1097/01.j.pain.0000460344.54470.20.

18. Gierthmühlen J, Binder A, Baron R. Mechanism-based treatment in complex regional pain syndromes. Nat Rev Neurol. 2014;10(9):518-28. https://doi.org/10.1038/nrneurol.2014.140.

19. Woolf CJ, Max MB. Mechanism-based pain diagnosis: issues for analgesic drug development. Anesthesiology. 2001;95(1):241-9. https://doi.org/10.1097/00000542-200107000-00034.

20. Huygen FJ, De Bruijn AG, De Bruin MT, Groeneweg JG, Klein J, Zijlstra FJ. Evidence for local inflammation in complex regional pain syndrome type 1. Mediators Inflamm. 2002;11(1):47-51. https://doi.org/10.1080/09629350210307.

21. de Mos M, Huygen F, Dieleman JP, Koopman J, Stricker CBH, Sturkenboom M. Medical history and the onset of complex regional pain syndrome (CRPS). Pain. 2008;139(2):458-66. https://doi.org/10.1016/j.pain.2008.07.002.

22. Wesseldijk F, Huygen FJ, Heijmans-Antonissen C, Niehof SP, Zijlstra FJ. Six years follow-up of the levels of TNF-alpha and IL-6 in patients with complex regional pain syndrome type 1 . Mediat Inflamm. 2008;2008: 469439. https://doi.org/10.1155/ 2008/469439.

23. David Clark J, Tawfik VL, Tajerian M, Kingery WS. Autoinflammatory and autoimmune contributions to complex regional pain syndrome. Mol Pain. 2018;14:1744806918799127. https://doi. org/10.1177/1744806918799127.

24. Birklein F, Drummond PD, Li W, Schlereth T, Albrecht N, Finch $\mathrm{PM}$, et al. Activation of cutaneous immune responses in complex regional pain syndrome. J Pain. 2014;15(5):485-95. https://doi. org/10.1016/j.jpain.2014.01.490.

25. Schinkel C, Gaertner A, Zaspel J, Zedler S, Faist E, Schuermann $\mathrm{M}$. Inflammatory mediators are altered in the acute phase of posttraumatic complex regional pain syndrome. Clin J Pain. 2006;22(3):235-9. https://doi.org/10.1097/01.ajp.0000169669. 70523.fo.

26. Alexander GM, van Rijn MA, van Hilten JJ, Perreault MJ, Schwartzman RJ. Changes in cerebrospinal fluid levels of proinflammatory cytokines in CRPS. Pain. 2005;116(3):213-9. https://doi.org/10.1016/j.pain.2005.04.013.

27. Alexander GM, Peterlin BL, Perreault MJ, Grothusen JR, Schwartzman RJ. Changes in plasma cytokines and their soluble receptors in complex regional pain syndrome. J Pain. 2012;13(1):10-20. https://doi.org/10.1016/j.jpain.2011.10.003.

28. Sommer C, Kress M. Recent findings on how proinflammatory cytokines cause pain: peripheral mechanisms in inflammatory and neuropathic hyperalgesia. Neurosci Lett. 2004;361(13):184-7. https://doi.org/10.1016/j.neulet.2003.12.007.

29. Ritz BW, Alexander GM, Nogusa S, Perreault MJ, Peterlin BL, Grothusen JR, et al. Elevated blood levels of inflammatory monocytes (CD14+ CD16+ ) in patients with complex regional pain syndrome. Clin Exp Immunol. 2011;164(1):108-17. https://doi. org/10.1111/j.1365-2249.2010.04308.x.

30. Bharwani KD, Dirckx M, Stronks DL, Dik WA, Schreurs MWJ, Huygen F. Elevated plasma levels of sIL-2R in complex regional pain syndrome: a pathogenic role for T-lymphocytes? Mediat Inflamm. 2017;2017:2764261. https://doi.org/10.1155/2017/ 2764261.

31. Heyn J, Azad SC, Luchting B. Altered regulation of the T-cell system in patients with CRPS. Inflamm Res. 2019;68(1):1-6. https://doi.org/10.1007/s00011-018-1182-3.

32. Dirckx M, Schreurs MW, de Mos M, Stronks DL, Huygen FJ. The prevalence of autoantibodies in complex regional pain syndrome type I. Mediat Inflamm. 2015;2015: 718201. https://doi. org/10.1155/2015/718201.

33. Birklein F, Schmelz M. Neuropeptides, neurogenic inflammation and complex regional pain syndrome (CRPS). Neurosci Lett. 2008;437(3):199-202. https://doi.org/10.1016/j.neulet.2008.03. 081.

34. Holzer P. Neurogenic vasodilatation and plasma leakage in the skin. Gen Pharmacol. 1998;30(1):5-11. https://doi.org/10.1016/ s0306-3623(97)00078-5.

35. Birklein F, Schmelz M, Schifter S, Weber M. The important role of neuropeptides in complex regional pain syndrome. Neurology. 2001;57(12):2179-84. https://doi.org/10.1212/wnl.57.12.2179.

36. Littlejohn G. Neurogenic neuroinflammation in fibromyalgia and complex regional pain syndrome. Nat Rev Rheumatol. 2015;11(11):639-48. https://doi.org/10.1038/nrrheum.2015.100.

37. Schlereth T, Dittmar JO, Seewald B, Birklein F. Peripheral amplification of sweating - a role for calcitonin gene-related peptide. J Physiol. 2006;576(3):823-32. https://doi.org/10.1113/jphysiol. 2006.116111. 
38. Prasad MdA, Chakravarthy MdK. Review of complex regional pain syndrome and the role of the neuroimmune axis. Mol Pain. 2021;17:17448069211006616. https://doi.org/10.1177/17448 069211006617.

39. Bharwani KD, Dik WA, Dirckx M, Huygen F. Highlighting the role of biomarkers of inflammation in the diagnosis and management of complex regional pain syndrome. Mol Diagn Ther. 2019;23(5):615-26. https://doi.org/10.1007/ s40291-019-00417-x.

40. Ji RR, Nackley A, Huh Y, Terrando N, Maixner W. Neuroinflammation and central sensitization in chronic and widespread pain. Anesthesiology. 2018;129(2):343-66. https://doi.org/10.1097/ ALN.0000000000002130.

41. Butovsky O, Weiner HL. Microglial signatures and their role in health and disease. Nat Rev Neurosci. 2018;19(10):622-35. https://doi.org/10.1038/s41583-018-0057-5.

42. Jeon SY, Seo S, Lee JS, Choi SH, Lee DH, Jung YH, et al. [11C](R)-PK11195 positron emission tomography in patients with complex regional pain syndrome: a pilot study. Medicine (Baltimore). 2017;96(1): e5735. https://doi.org/10.1097/MD.00000 00000005735.

43. Park JY, Ahn RS. Hypothalamic-pituitary-adrenal axis function in patients with complex regional pain syndrome type 1 . Psychoneuroendocrinology. 2012;37(9):1557-68. https://doi.org/ 10.1016/j.psyneuen.2012.02.016.

44. Cain DW, Cidlowski JA. Immune regulation by glucocorticoids. Nat Rev Immunol. 2017;17(4):233-47. https://doi.org/10.1038/ nri.2017.1.

45. Buryanov A, Kostrub A, Kotiuk V. Endocrine disorders in women with complex regional pain syndrome type I. Eur J Pain. 2017;21(2):302-8. https://doi.org/10.1002/ejp.924.

46. $\mathrm{Li} \mathrm{X}, \mathrm{Hu} \mathrm{L}$. The role of stress regulation on neural plasticity in pain chronification. Neural Plast. 2016;2016:6402942. https:// doi.org/10.1155/2016/6402942.

47. Goebel A, Blaes F. Complex regional pain syndrome, prototype of a novel kind of autoimmune disease. Autoimmun Rev. 2013;12(6):682-6. https://doi.org/10.1016/j.autrev.2012.10.015.

48. Doria A, Zen M, Bettio S, Gatto M, Bassi N, Nalotto L, et al. Autoinflammation and autoimmunity: bridging the divide. Autoimmun Rev. 2012;12(1):22-30. https://doi.org/10.1016/j.autrev. 2012.07.018.

49. Kohr D, Tschernatsch M, Schmitz K, Singh P, Kaps M, Schafer $\mathrm{KH}$, et al. Autoantibodies in complex regional pain syndrome bind to a differentiation-dependent neuronal surface autoantigen. Pain. 2009;143(3):246-51. https://doi.org/10.1016/j.pain.2009. 03.009 .

50. Dubuis E, Thompson V, Leite MI, Blaes F, Maihöfner C, Greensmith $\mathrm{D}$, et al. Longstanding complex regional pain syndrome is associated with activating autoantibodies against alpha-1a adrenoceptors. Pain. 2014;155(11):2408-17. https://doi.org/10. 1016/j.pain.2014.09.022.

51. Cuhadar U, Gentry C, Vastani N, Sensi S, Bevan S, Goebel A, et al. Autoantibodies produce pain in complex regional pain syndrome by sensitizing nociceptors. Pain. 2019;160(12):2855-65. https://doi.org/10.1097/j.pain.0000000000001662.

52. Dirckx M, Stronks DL, Groeneweg G, Huygen FJ. Effect of immunomodulating medications in complex regional pain syndrome: a systematic review. Clin J Pain. 2012;28(4):355-63. https://doi.org/10.1097/AJP.0b013e31822efe30.

53. Christensen K, Jensen EM, Noer I. The reflex dystrophy syndrome response to treatment with systemic corticosteroids. Acta Chir Scand. 1982;148(8):653-5.

54. Barbalinardo S, Loer SA, Goebel A, Perez RS. The treatment of longstanding complex regional pain syndrome with oral steroids. Pain Med. 2016;17(2):337-43. https://doi.org/10.1093/pm/ pnv002.
55. Harden RN, Oaklander AL, Burton AW, Perez RS, Richardson $\mathrm{K}$, Swan M, et al. Complex regional pain syndrome: practical diagnostic and treatment guidelines, 4th edition. Pain Med. 2013;14(2):180-229. https://doi.org/10.1111/pme.12033.

56. Calvo M, Dawes JM, Bennett DL. The role of the immune system in the generation of neuropathic pain. Lancet Neurol. 2012;11(7):629-42. https://doi.org/10.1016/S1474-4422(12) 70134-5.

57. Fitzcharles MA, Cohen SP, Clauw DJ, Littlejohn G, Usui C, Hauser W. Nociplastic pain: towards an understanding of prevalent pain conditions. Lancet. 2021;397(10289):2098-110. https:// doi.org/10.1016/S0140-6736(21)00392-5.

58. Munts AG, van der Plas AA, Ferrari MD, Teepe-Twiss IM, Marinus J, van Hilten JJ. Efficacy and safety of a single intrathecal methylprednisolone bolus in chronic complex regional pain syndrome. Eur J Pain. 2010;14(5):523-8. https://doi.org/10.1016/j. ejpain.2009.11.004.

59. Rijsdijk M, van Wijck AJM, Kalkman Cor J, Meulenhoff PCW, Grafe Marjorie R, Steinauer J, et al. Safety assessment and pharmacokinetics of intrathecal methylprednisolone acetate in dogs. Anesthesiology. 2012;116(1):170-81. https://doi.org/10.1097/ ALN.0b013e31823cf035.

60. Basle MF, Rebel A, Renier JC. Bone tissue in reflex sympathetic dystrophy syndrome-Sudeck's atrophy: structural and ultrastructural studies. Metab Bone Dis Relat Res. 1983;4(5):305-11. https://doi.org/10.1016/S0221-8747(83)80004-6.

61. Varenna M, Zucchi F, Ghiringhelli D, Binelli L, Bevilacqua M, Bettica $\mathrm{P}$, et al. Intravenous clodronate in the treatment of reflex sympathetic dystrophy syndrome. A randomized, double blind, placebo controlled study. J Rheumatol. 2000;27(6):1477-83.

62. Varenna M, Adami S, Sinigaglia L. Bisphosphonates in complex regional pain syndrome type I: how do they work. Clin Exp Rheumatol. 2014;32(4):451-4.

63. Tzschentke TM. Pharmacology of bisphosphonates in pain. Br J Pharmacol. 2021;178(9):1973-94. https://doi.org/10.1111/bph. 14799.

64. Maksymowych WP. Bisphosphonates-anti-inflammatory properties. Curr Med Chem Anti-Inflamm Anti-Allergy Agents. 2002;1(1):15-28. https://doi.org/10.2174/1568014024606539.

65. Chevreau M, Romand X, Gaudin P, Juvin R, Baillet A. Bisphosphonates for treatment of complex regional pain syndrome type 1: a systematic literature review and meta-analysis of randomized controlled trials versus placebo. Jt Bone Spine. 2017;84(4):3939. https://doi.org/10.1016/j.jbspin.2017.03.009.

66. Manicourt DH, Brasseur JP, Boutsen Y, Depreseux G, Devogelaer JP. Role of alendronate in therapy for posttraumatic complex regional pain syndrome type I of the lower extremity. Arthritis Rheum. 2004;50(11):3690-7. https://doi.org/10.1002/art.20591.

67. Robinson JN, Sandom J, Chapman PT. Efficacy of pamidronate in complex regional pain syndrome type I. Pain Med. 2004;5(3):276-80. https://doi.org/10.1111/j.1526-4637.2004. 04038.x.

68. Varenna M, Adami S, Rossini M, Gatti D, Idolazzi L, Zucchi $\mathrm{F}$, et al. Treatment of complex regional pain syndrome type I with neridronate: a randomized, double-blind, placebo-controlled study. Rheumatology (Oxford). 2013;52(3):534-42. https://doi. org/10.1093/rheumatology/kes312.

69. Varenna M, Manara M, Rovelli F, Zucchi F, Sinigaglia L. Predictors of responsiveness to bisphosphonate treatment in patients with complex regional pain syndrome type I: a retrospective chart analysis. Pain Med. 2017;18(6):1131-8. https://doi.org/ 10.1093/pm/pnw207.

70. Kapural L, Goebel A, Serpell M, Jones A, Kaye R, Tabuteau H. CREATE-1 study: a randomized, double-blind, placebo-controlled study to assess the efficacy and safety of AXS-02 (disodium zoledronate tetrahydrate) administered orally to subjects 
with Complex Regional Pain Syndrome Type 1 (CRPS-1). J Pain. 2016;17(4 Suppl):S81-2. https://doi.org/10.1016/j.jpain.2016.01. 406.

71. Carr A, Frei B. Does vitamin $\mathrm{C}$ act as a pro-oxidant under physiological conditions? FASEB J. 1999;13(9):1007-24. https://doi. org/10.1096/fasebj.13.9.1007.

72. van der Laan L, Goris RJ. Reflex sympathetic dystrophy. An exaggerated regional inflammatory response? Hand Clin. 1997;13(3):373-85. https://doi.org/10.1016/S0749-0712(21) 00099-8.

73. Zuurmond WW, Langendijk PN, Bezemer PD, Brink HE, de Lange JJ, van Loenen AC. Treatment of acute reflex sympathetic dystrophy with DMSO 50\% in a fatty cream. Acta Anaesthesiol Scand. 1996;40(3):364-7. https://doi.org/10.1111/j.1399-6576. 1996.tb04446.x.

74. Perez M, Zuurmond AWW, Bezemer DP, Kuik JD, van Loenen CA, de Lange JJ, et al. The treatment of complex regional pain syndrome type I with free radical scavengers: a randomized controlled study. Pain. 2003;102(3):297-307. https://doi.org/ 10.1016/S0304-3959(02)00414-1.

75. Buettner GR. The pecking order of free radicals and antioxidants: lipid peroxidation, alpha-tocopherol, and ascorbate. Arch Biochem Biophys. 1993;300(2):535-43. https://doi.org/10.1006/ abbi.1993.1074.

76. Zollinger PE, Tuinebreijer WE, Kreis RW, Breederveld RS. Effect of vitamin C on frequency of reflex sympathetic dystrophy in wrist fractures: a randomised trial. Lancet. 1999;354(9195):2025-8. https://doi.org/10.1016/S01406736(99)03059-7.

77. Zollinger PE, Tuinebreijer WE, Breederveld RS, Kreis RW. Can vitamin $\mathrm{C}$ prevent complex regional pain syndrome in patients with wrist fractures? A randomized, controlled, multicenter doseresponse study. JBJS. 2007;89(7):1424-31. https://doi.org/10. 2106/JBJS.F.01147.

78. Ekrol I, Duckworth AD, Ralston SH, Court-Brown CM, McQueen MM. The influence of vitamin $\mathrm{C}$ on the outcome of distal radial fractures: a double-blind, randomized controlled trial. J Bone Jt Surg Am. 2014;96(17):1451-9. https://doi.org/ 10.2106/JBJS.M.00268.

79. Aim F, Klouche S, Frison A, Bauer T, Hardy P. Efficacy of vitamin $\mathrm{C}$ in preventing complex regional pain syndrome after wrist fracture: a systematic review and meta-analysis. Orthop Traumatol Surg Res. 2017;103(3):465-70. https://doi.org/10.1016/j.otsr. 2016.12.021.

80. Meena S, Sharma P, Gangary SK, Chowdhury B. Role of vitamin $\mathrm{C}$ in prevention of complex regional pain syndrome after distal radius fractures: a meta-analysis. Eur J Orthop Surg Traumatol. 2015;25(4):637-41. https://doi.org/10.1007/s00590-014-1573-2.

81. Shibuya N, Humphers JM, Agarwal MR, Jupiter DC. Efficacy and safety of high-dose vitamin $\mathrm{C}$ on complex regional pain syndrome in extremity trauma and surgery-systematic review and meta-analysis. J Foot Ankle Surg. 2013;52(1):62-6. https://doi. org/10.1053/j.jfas.2012.08.003.

82. Goebel A, Barker CH, Turner-Stokes L. Complex regional pain syndrome in adults: UK guidelines for diagnosis, referral and management in primary and secondary care. London: RcP; 2018.

83. Lichtman DM, Bindra RR, Boyer MI, Putnam MD, Ring D, Slutsky DJ, et al. Treatment of distal radius fractures. J Am Acad Orthop Surg. 2010;18(3):180-9. https://doi.org/10.5435/00124 635-201003000-00007.

84. Krämer HH, Eberle T, Üçeyler N, Wagner I, Klonschinsky T, Müller LP, et al. TNF-alpha in CRPS and 'normal' traumasignificant differences between tissue and serum. Pain. 2011;152(2):285-90. https://doi.org/10.1016/j.pain.2010.09.024.

85. Kirkham B. Tumor necrosis factor-alpha inhibitors: An overview of adverse effects. 29 Sep 2021. https://www.uptodate.com/conte nts/tumor-necrosis-factor-alpha-inhibitors-an-overview-of-adver se-effects. Accessed 29 Sept 2021.

86. Huygen FJ, Niehof S, Zijlstra FJ, van Hagen PM, van Daele PL. Successful treatment of CRPS 1 with anti-TNF. J Pain Symptom Manag. 2004;27(2):101-3. https://doi.org/10.1016/j.jpainsymman.2003.12.006.

87. Dirckx M, Groeneweg G, Wesseldijk F, Stronks DL, Huygen FJ. Report of a preliminary discontinued double-blind, randomized, placebo-controlled trial of the anti-TNF-alpha chimeric monoclonal antibody infliximab in complex regional pain syndrome. Pain Pract. 2013;13(8):633-40. https://doi.org/10.1111/papr.12078.

88. Eisenberg E, Sandler I, Treister R, Suzan E, Haddad M. Anti tumor necrosis factor - alpha adalimumab for complex regional pain syndrome type 1 (CRPS-I): a case series. Pain Pract. 2013;13(8):649-56. https://doi.org/10.1111/papr.12070.

89. Asher C, Furnish T. Lenalidomide and thalidomide in the treatment of chronic pain. Expert Opin Drug Saf. 2013;12(3):367-74. https://doi.org/10.1517/14740338.2013.775242.

90. Schwartzman RJ, Chevlen E, Bengtson K. Thalidomide has activity in treating complex regional pain syndrome. Arch Intern Med. 2003;163(12):1487-8. https://doi.org/10.1001/archinte.163.12. 1487.

91. Schwartzman RJ, Irving G, Wallace M, Rauck R, Dogra S, Raja $\mathrm{S}$, et al. A multicenter, open label, 12 week study with extension to evaluate the safety and efficacy of lenalidomide (CC5013) in the treatment of complex regional pain syndrome type-I [abstract]. In: 11th World Congress on Pain; 2005. p. 580.

92. Manning DC, Alexander G, Arezzo JC, Cooper A, Harden RN, Oaklander AL, et al. Lenalidomide for complex regional pain syndrome type 1: lack of efficacy in a phase II randomized study. J Pain. 2014;15(12):1366-76. https://doi.org/10.1016/j.jpain. 2014.09.013.

93. Aradillas E, Schwartzman RJ, Grothusen JR, Goebel A, Alexander GM. Plasma exchange therapy in patients with complex regional pain syndrome. Pain Physician. 2015;18(4):383-94.

94. Goebel A, Bisla J, Carganillo R, Frank B, Gupta R, Kelly J, et al. Low-dose intravenous immunoglobulin treatment for longstanding complex regional pain syndrome: a randomized trial. Ann Intern Med. 2017;167(7):476-83. https://doi.org/10.7326/ M17-0509.

95. Oaklander AL, Rissmiller JG, Gelman LB, Zheng L, Chang Y, Gott R. Evidence of focal small-fiber axonal degeneration in complex regional pain syndrome-I (reflex sympathetic dystrophy). Pain. 2006;120(3):235-43. https://doi.org/10.1016/j.pain. 2005.09.036.

96. Albrecht PJ, Hines S, Eisenberg E, Pud D, Finlay DR, Connolly $\mathrm{KM}$, et al. Pathologic alterations of cutaneous innervation and vasculature in affected limbs from patients with complex regional pain syndrome. Pain. 2006;120(3):244-66. https://doi.org/10. 1016/j.pain.2005.10.035.

97. van der Laan L, ter Laak HJ, Gabreels-Festen A, Gabreels F, Goris RJ. Complex regional pain syndrome type I (RSD): pathology of skeletal muscle and peripheral nerve. Neurology. 1998;51(1):20-5. https://doi.org/10.1212/wnl.51.1.20.

98. Knudsen LF, Terkelsen AJ, Drummond PD, Birklein F. Complex regional pain syndrome: a focus on the autonomic nervous system. Clin Auton Res. 2019;29(4):457-67. https://doi.org/10. 1007/s10286-019-00612-0.

99. Drummond PD, Drummond ES, Dawson LF, Mitchell V, Finch PM, Vaughan CW, et al. Upregulation of $\alpha 1$-adrenoceptors on cutaneous nerve fibres after partial sciatic nerve ligation and in complex regional pain syndrome type II. Pain. 2014;155(3):60616. https://doi.org/10.1016/j.pain.2013.12.021.

100. Drummond ES, Dawson LF, Finch PM, Bennett GJ, Drummond PD. Increased expression of cutaneous $\alpha 1$-adrenoceptors after 
chronic constriction injury in rats. J Pain. 2014;15(2):188-96. https://doi.org/10.1016/j.jpain.2013.10.010.

101. Mailis-Gagnon A, Bennett GJ. Abnormal contralateral pain responses from an intradermal injection of phenylephrine in a subset of patients with complex regional pain syndrome (CRPS). Pain. 2004;111(3):378-84. https://doi.org/10.1016/j.pain.2004. 07.019.

102. Ali Z, Raja SN, Wesselmann U, Fuchs PN, Meyer RA, Campbell JN. Intradermal injection of norepinephrine evokes pain in patients with sympathetically maintained pain. Pain. 2000;88(2):161-8. https://doi.org/10.1016/S0304-3959(00) 00327-4.

103. Woolf CJ. Central sensitization: implications for the diagnosis and treatment of pain. Pain. 2011;152(3 Suppl):S2-15. https:// doi.org/10.1016/j.pain.2010.09.030.

104. Yang Y, Maher DP, Cohen SP. Emerging concepts on the use of ketamine for chronic pain. Expert Rev Clin Pharmacol. 2020;13(2):135-46. https://doi.org/10.1080/17512433.2020. 1717947.

105. Sieweke N, Birklein F, Riedl B, Neundorfer B, Handwerker HO. Patterns of hyperalgesia in complex regional pain syndrome. Pain. 1999;80(1-2):171-7. https://doi.org/10.1016/s03043959(98)00200-0.

106. Graven-Nielsen T, Arendt-Nielsen L. Assessment of mechanisms in localized and widespread musculoskeletal pain. Nat Rev Rheumatol. 2010;6(10):599-606. https://doi.org/10.1038/nrrheum. 2010.107.

107. Di Pietro F, McAuley JH, Parkitny L, Lotze M, Wand BM, Moseley GL, et al. Primary somatosensory cortex function in complex regional pain syndrome: a systematic review and meta-analysis. J Pain. 2013;14(10):1001-18. https://doi.org/10.1016/j.jpain.2013. 04.001.

108. Di Pietro F, McAuley JH, Parkitny L, Lotze M, Wand BM, Moseley GL, et al. Primary motor cortex function in complex regional pain syndrome: a systematic review and meta-analysis. J Pain. 2013;14(11):1270-88. https://doi.org/10.1016/j.jpain.2013.07. 004.

109. Di Pietro F, Stanton TR, Moseley GL, Lotze M, McAuley JH. Interhemispheric somatosensory differences in chronic pain reflect abnormality of the healthy side. Hum Brain Mapp. 2015;36(2):508-18. https://doi.org/10.1002/hbm.22643.

110. Maihöfner C, Handwerker HO, Neundörfer B, Birklein F. Patterns of cortical reorganization in complex regional pain syndrome. Neurology. 2003;61(12):1707-15. https://doi.org/10. 1212/01.WNL.0000098939.02752.8E.

111. Freund W, Wunderlich AP, Stuber G, Mayer F, Steffen P, Mentzel $\mathrm{M}$, et al. The role of periaqueductal gray and cingulate cortex during suppression of pain in complex regional pain syndrome. Clin J Pain. 2011;27(9):796-804. https://doi.org/10.1097/AJP. 0b013e31821d9063.

112. Klega A, Eberle T, Buchholz HG, Maus S, Maihofner C, Schreckenberger M, et al. Central opioidergic neurotransmission in complex regional pain syndrome. Neurology. 2010;75(2):129_ 36. https://doi.org/10.1212/WNL.0b013e3181e7ca2e.

113. Geha PY, Baliki MN, Harden RN, Bauer WR, Parrish TB, Apkarian AV. The brain in chronic CRPS pain: abnormal gray-white matter interactions in emotional and autonomic regions. Neuron. 2008;60(4):570-81. https://doi.org/10.1016/j.neuron.2008.08. 022 .

114. Barad MJ, Ueno T, Younger J, Chatterjee N, Mackey S. Complex regional pain syndrome is associated with structural abnormalities in pain-related regions of the human brain. J Pain. 2014;15(2):197-203. https://doi.org/10.1016/j.jpain.2013.10. 011.

115. Riedl B, Beckmann T, Neundörfer B, Handwerker HO, Birklein F. Autonomic failure after stroke-is it indicative for pathophysiology of complex regional pain syndrome? Acta Neurol Scand. 2001;103(1):27-34. https://doi.org/10.1034/j. 1600-0404.2001.00139.x

116. Pleger B, Tegenthoff M, Ragert P, Förster AF, Dinse HR, Schwenkreis $\mathrm{P}$, et al. Sensorimotor returning in complex regional pain syndrome parallels pain reduction. Ann Neurol. 2005;57(3):425-9. https://doi.org/10.1002/ana.20394.

117. Donvito G, Nass SR, Wilkerson JL, Curry ZA, Schurman LD, Kinsey SG, et al. The endogenous cannabinoid system: a budding source of targets for treating inflammatory and neuropathic pain. Neuropsychopharmacology. 2018;43(1):52-79. https://doi.org/ 10.1038/npp.2017.204.

118. Rani Sagar D, Burston JJ, Woodhams SG, Chapman V. Dynamic changes to the endocannabinoid system in models of chronic pain. Philos Trans R Soc Lond B Biol Sci. 2012;367(1607):3300_ 11. https://doi.org/10.1098/rstb.2011.0390.

119. Stella B, Baratta F, Della Pepa C, Arpicco S, Gastaldi D, Dosio F. Cannabinoid formulations and delivery systems: current and future options to treat pain. Drugs. 2021;81(13):1513-57. https:// doi.org/10.1007/s40265-021-01579-x.

120. Duffy SS, Hayes JP, Fiore NT, Moalem-Taylor G. The cannabinoid system and microglia in health and disease. Neuropharmacology. 2021;190: 108555. https://doi.org/10.1016/j.neuropharm. 2021.108555

121. Xu J, Tang Y, Xie M, Bie B, Wu J, Yang H, et al. Activation of cannabinoid receptor 2 attenuates mechanical allodynia and neuroinflammatory responses in a chronic post-ischemic pain model of complex regional pain syndrome type I in rats. Eur J Neurosci. 2016;44(12):3046-55. https://doi.org/10.1111/ejn.13414.

122. Kaufmann I, Hauer D, Huge V, Vogeser M, Campolongo P, Chouker A, et al. Enhanced anandamide plasma levels in patients with complex regional pain syndrome following traumatic injury: a preliminary report. Eur Surg Res. 2009;43(4):325-9. https:// doi.org/10.1159/000235870.

123. Dworkin RH, O’Connor AB, Backonja M, Farrar JT, Finnerup $\mathrm{NB}$, Jensen TS, et al. Pharmacologic management of neuropathic pain: evidence-based recommendations. Pain. 2007;132(3):23751. https://doi.org/10.1016/j.pain.2007.08.033.

124. Bennett MI, Simpson KH. Gabapentin in the treatment of neuropathic pain. Palliat Med. 2004;18(1):5-11. https://doi.org/10. 1191/0269216304pm845ra.

125. van Vusse AC, Stomp-van den Berg SG, Kessels AH, Weber WE. Randomised controlled trial of gabapentin in Complex Regional Pain Syndrome type 1 [ISRCTN84121379]. BMC Neurol. 2004;4(1):13. https://doi.org/10.1186/1471-2377-4-13.

126. Tan AK, Duman I, Taskaynatan MA, Hazneci B, Kalyon TA. The effect of gabapentin in earlier stage of reflex sympathetic dystrophy. Clin Rheumatol. 2007;26(4):561-5. https://doi.org/ 10.1007/s10067-006-0350-y.

127. Brown S, Johnston B, Amaria K, Watkins J, Campbell F, Pehora $\mathrm{C}$, et al. A randomized controlled trial of amitriptyline versus gabapentin for complex regional pain syndrome type I and neuropathic pain in children. Scand J Pain. 2016;13:156-63. https:// doi.org/10.1016/j.sjpain.2016.05.039.

128. Javed S, Abdi S. Use of anticonvulsants and antidepressants for treatment of complex regional pain syndrome: a literature review. Pain Manag. 2021;11(2):189-99. https://doi.org/10.2217/ pmt-2020-0060.

129. Mangnus TJP, Dirckx M, Bharwani KD, de Vos CC, Frankema SPG, Stronks DL, et al. Effect of intravenous low-dose S-ketamine on pain in patients with complex regional pain syndrome: a retrospective cohort study. Pain Pract. 2021;21(8):890-7. https:// doi.org/10.1111/papr.13056.

130. Sigtermans MJ, van Hilten JJ, Bauer MCR, Arbous SM, Marinus J, Sarton EY, et al. Ketamine produces effective and long-term pain relief in patients with Complex Regional Pain Syndrome 
Type 1. Pain. 2009;145(3):304-11. https://doi.org/10.1016/j. pain.2009.06.023.

131. Kamp J, Van Velzen M, Olofsen E, Boon M, Dahan A, Niesters M. Pharmacokinetic and pharmacodynamic considerations for NMDA-receptor antagonist ketamine in the treatment of chronic neuropathic pain: an update of the most recent literature. Expert Opin Drug Metab Toxicol. 2019;15(12):1033-41. https://doi.org/ 10.1080/17425255.2019.1689958.

132. Loix S, De Kock M, Henin P. The anti-inflammatory effects of ketamine: state of the art. Acta Anaesthesiol Belg. 2011;62(1):47-58.

133. Strasburger SE, Bhimani PM, Kaabe JH, Krysiak JT, Nanchanatt DL, Nguyen TN, et al. What is the mechanism of ketamine's rapid-onset antidepressant effect? A concise overview of the surprisingly large number of possibilities. J Clin Pharm Ther. 2017;42(2):147-54. https://doi.org/10.1111/jcpt.12497.

134. Sorel M, Zrek N, Locko B, Armessen C, Ayache SS, Lefaucheur JP. A reappraisal of the mechanisms of action of ketamine to treat complex regional pain syndrome in the light of cortical excitability changes. Clin Neurophysiol. 2018;129(5):990-1000. https://doi.org/10.1016/j.clinph.2018.02.124.

135. Cohen SP, Bhatia A, Buvanendran A, Schwenk ES, Wasan AD, Hurley RW, et al. Consensus guidelines on the use of intravenous ketamine infusions for chronic pain from the American Society of Regional Anesthesia and Pain Medicine, the American Academy of Pain Medicine, and the American Society of Anesthesiologists. Reg Anesth Pain Med. 2018;43(5):521-46. https://doi. org/10.1097/AAP.0000000000000808.

136. Schwartzman RJ, Alexander GM, Grothusen JR, Paylor T, Reichenberger E, Perreault M. Outpatient intravenous ketamine for the treatment of complex regional pain syndrome: a doubleblind placebo controlled study. Pain. 2009;147(1-3):107-15. https://doi.org/10.1016/j.pain.2009.08.015.

137. Zhao J, Wang Y, Wang D. The effect of ketamine infusion in the treatment of complex regional pain syndrome: a systemic review and meta-analysis. Curr Pain Headache Rep. 2018;22(2):12. https://doi.org/10.1007/s11916-018-0664-x.

138. Noppers IM, Niesters M, Aarts L, Bauer MCR, Drewes AM, Dahan A, et al. Drug-induced liver injury following a repeated course of ketamine treatment for chronic pain in CRPS type 1 patients: a report of 3 cases. Pain. 2011;152(9):2173-8. https:// doi.org/10.1016/j.pain.2011.03.026.

139. Mangnus TJP, Bharwani KD, Stronks DL, Dirckx M, Huygen FJPM. Ketamine therapy for chronic pain in The Netherlands: a nationwide survey. Scand J Pain. 2022;22(1):97-105. https://doi. org/10.1515/sjpain-2021-0079.

140. Jonkman K, Duma A, Velzen M, Dahan A. Ketamine inhalation. Br J Anaesth. 2017;118(2):268-9. https://doi.org/10.1093/bja/ aew457.

141. Chong CC, Schug SA. Efficacy and tolerability of oral compared with sublingual ketamine lozenges as rescue analgesics in adults for acute pain: the OSKet trial. Clin Drug Investig. 2021. https:// doi.org/10.1007/s40261-021-01066-x.

142. Finch PM, Knudsen L, Drummond PD. Reduction of allodynia in patients with complex regional pain syndrome: a double-blind placebo-controlled trial of topical ketamine. Pain. 2009;146(12):18-25. https://doi.org/10.1016/j.pain.2009.05.017.

143. Blonk MI, Koder BG, van den Bemt PM, Huygen FJ. Use of oral ketamine in chronic pain management: a review. Eur J Pain. 2010;14(5):466-72. https://doi.org/10.1016/j.ejpain.2009.09. 005 .

144. Marchetti F, Coutaux A, Bellanger A, Magneux C, Bourgeois $\mathrm{P}$, Mion G. Efficacy and safety of oral ketamine for the relief of intractable chronic pain: a retrospective 5-year study of 51 patients. Eur J Pain. 2015;19(7):984-93. https://doi.org/10.1002/ ejp.624.
145. Furuhashi-Yonaha A, Iida H, Asano T, Takeda T, Dohi S. Shortand long-term efficacy of oral ketamine in eight chronic-pain patients. Can J Anaesth. 2002;49(8):886-7. https://doi.org/10. 1007/BF03017431.

146. Rigo FK, Trevisan G, Godoy MC, Rossato MF, Dalmolin GD, Silva MA, et al. Management of neuropathic chronic pain with methadone combined with ketamine: a randomized, double blind, active-controlled clinical trial. Pain Physician. 2017;20(3):207-15.

147. Krcevski-Skvarc N, Wells C, Hauser W. Availability and approval of cannabis-based medicines for chronic pain management and palliative/supportive care in Europe: a survey of the status in the chapters of the European Pain Federation. Eur J Pain. 2018;22(3):440-54. https://doi.org/10.1002/ejp.1147.

148. Hauser W, Finn DP, Kalso E, Krcevski-Skvarc N, Kress HG, Morlion B, et al. European Pain Federation (EFIC) position paper on appropriate use of cannabis-based medicines and medical cannabis for chronic pain management. Eur J Pain. 2018;22(9):1547-64. https://doi.org/10.1002/ejp.1297.

149. Wilsey B, Marcotte T, Deutsch R, Gouaux B, Sakai S, Donaghe H. Low-dose vaporized cannabis significantly improves neuropathic pain. J Pain. 2013;14(2):136-48. https://doi.org/10.1016/j. jpain.2012.10.009.

150. Wilsey B, Marcotte T, Tsodikov A, Millman J, Bentley H, Gouaux B, et al. A randomized, placebo-controlled, crossover trial of cannabis cigarettes in neuropathic pain. J Pain. 2008;9(6):50621. https://doi.org/10.1016/j.jpain.2007.12.010.

151. Almog S, Aharon-Peretz J, Vulfsons S, Ogintz M, Abalia H, Lupo T, et al. The pharmacokinetics, efficacy, and safety of a novel selective-dose cannabis inhaler in patients with chronic pain: a randomized, double-blinded, placebo-controlled trial. Eur J Pain. 2020;24(8):1505-16. https://doi.org/10.1002/ejp.1605.

152. Meng H, Johnston B, Englesakis M, Moulin DE, Bhatia A. Selective cannabinoids for chronic neuropathic pain: a systematic review and meta-analysis. Anesth Analg. 2017;125(5):1638-52. https://doi.org/10.1213/ANE.0000000000002110.

153. Aviram J, Samuelly-Leichtag G. Efficacy of cannabis-based medicines for pain management: a systematic review and meta-analysis of randomized controlled trials. Pain Physician. 2017;20(6):E755-96.

154. Iskedjian M, Bereza B, Gordon A, Piwko C, Einarson TR. Metaanalysis of cannabis based treatments for neuropathic and multiple sclerosis-related pain. Curr Med Res Opin. 2007;23(1):1724. https://doi.org/10.1185/030079906x158066.

155. Mücke M, Phillips T, Radbruch L, Petzke F, Häuser W. Cannabis-based medicines for chronic neuropathic pain in adults. Cochrane Database Syst Rev. 2018;3:CD012182. https://doi.org/ 10.1002/14651858.CD012182.pub2.

156. Johal H, Devji T, Chang Y, Simone J, Vannabouathong C, Bhandari M. Cannabinoids in chronic non-cancer pain: a systematic review and meta-analysis. Clin Med Insights Arthritis Musculoskelet Disord. 2020;13:1179544120906461. https://doi. org/10.1177/1179544120906461.

157. Chang Y, Zhu M, Vannabouathong C, Mundi R, Chou RS, Bhandari M. Medical cannabis for chronic noncancer pain: a systematic review of health care recommendations. Pain Res Manag. 2021;2021:8857948. https://doi.org/10.1155/2021/8857948.

158. Urquhart L. FDA new drug approvals in Q1 2019. Nat Rev Drug Discov. 2019. https://doi.org/10.1038/d41573-019-00070-3 (Epub 10 Apr 2019).

159. Carr DB, Goudas LC, Denman WT, Brookoff D, Staats PS, Brennen L, et al. Safety and efficacy of intranasal ketamine for the treatment of breakthrough pain in patients with chronic pain: a randomized, double-blind, placebo-controlled, crossover study. Pain. 2004;108(1-2):17-27. https://doi.org/10.1016/j.pain.2003. 07.001 . 
160. Huge V, Lauchart M, Magerl W, Schelling G, Beyer A, Thieme $\mathrm{D}$, et al. Effects of low-dose intranasal (S)-ketamine in patients with neuropathic pain. Eur J Pain. 2010;14(4):387-94. https:// doi.org/10.1016/j.ejpain.2009.08.002.

161. Sanacora G, Smith MA, Pathak S, Su HL, Boeijinga PH, McCarthy DJ, et al. Lanicemine: a low-trapping NMDA channel blocker produces sustained antidepressant efficacy with minimal psychotomimetic adverse effects. Mol Psychiatry. 2014;19(9):978-85. https://doi.org/10.1038/mp.2013.130.

162. Intellectual property. [cited 24 Sep 2021]. https://www.bioha venpharma.com/science-pipeline/resources/intellectual-prope rty. Accessed 24 Sept 2021.

163. Global Complex Regional Pain Syndrome (CRPS) Market Insights, Epidemiology and Market Forecast Report 2017-2030. 2021 [cited 24 Sep 2021]. https://www.businesswire.com/news/ home/20210202005946/en/Global-Complex-Regional-PainSyndrome-CRPS-Market-Insights-Epidemiology-and-Market-Forecast-Report-2017-2030---ResearchAndMarkets.com. Accessed 24 Sept 2021.

164. Biohaven Pharmaceutical Holding Annual Report 2021. 2021 [24 Sep 2021]. https://annualreport.stocklight.com/NYSE/BHVN/ 21699182.pdf. Accessed 24 Sept 2021.

165. Steriade C, French J, Devinsky O. Epilepsy: key experimental therapeutics in early clinical development. Expert Opin Investig Drugs. 2020;29(4):373-83. https://doi.org/10.1080/13543784. 2020.1743678 .

166. Perry MS. New and emerging medications for treatment of pediatric epilepsy. Pediatr Neurol. 2020;107:24-7. https://doi.org/10. 1016/j.pediatrneurol.2019.11.008.

167. Halford JJ, Sperling MR, Arkilo D, Asgharnejad M, Zinger C, Xu $\mathrm{R}$, et al. A phase $1 \mathrm{~b} / 2 \mathrm{a}$ study of soticlestat as adjunctive therapy in participants with developmental and/or epileptic encephalopathies. Epilepsy Res. 2021;174: 106646. https://doi.org/10.1016/j. eplepsyres.2021.106646.

168. Wesseldijk F, Fekkes D, Huygen FJ, van de Heide-Mulder M, Zijlstra FJ. Increased plasma glutamate, glycine, and arginine levels in complex regional pain syndrome type 1. Acta Anaesthesiol Scand. 2008;52(5):688-94. https://doi.org/10.1111/j.13996576.2008.01638.x.

169. Study of TAK-935 as an Adjunctive Therapy in Adult Participants With Complex Regional Pain Syndrome (CRPS). 15-072021 [cited 24 Sep 2021]. https://clinicaltrials.gov/ct2/show/ NCT03990649. Accessed 24 Sept 2021.

170. Kortekaas MC, Niehof SP, Stolker RJ, Huygen FJ. Pathophysiological mechanisms involved in vasomotor disturbances in complex regional pain syndrome and implications for therapy: a review. Pain Pract. 2016;16(7):905-14. https://doi.org/10.1111/ papr. 12403

171. Wasner G. Vasomotor disturbances in complex regional pain syndrome-a review. Pain Med. 2010;11(8):1267-73. https:// doi.org/10.1111/j.1526-4637.2010.00914.x.

172. Drummond PD, Finch PM, Smythe GA. Reflex sympathetic dystrophy: the significance of differing plasma catecholamine concentrations in affected and unaffected limbs. Brain. 1991;114(Pt 5):2025-36. https://doi.org/10.1093/brain/114.5.2025.

173. Drummond PD, Finch PM, Edvinsson L, Goadsby PJ. Plasma neuropeptide $\mathrm{Y}$ in the symptomatic limb of patients with causalgic pain. Clin Auton Res. 1994;4(3):113-6. https://doi.org/ 10.1007/BF01845774.

174. Drummond PD. Neuronal changes resulting in up-regulation of alpha-1 adrenoceptors after peripheral nerve injury. Neural Regen Res. 2014;9(14):1337-40. https://doi.org/10.4103/16735374.137583.

175. Arnold JM, Teasell RW, MacLeod AP, Brown JE, Carruthers SG. Increased venous alpha-adrenoceptor responsiveness in patients with reflex sympathetic dystrophy. Ann Intern Med.
1993;118(8):619-21. https://doi.org/10.7326/0003-4819-1188-199304150-00008.

176. Koban M, Leis S, Schultze-Mosgau S, Birklein F. Tissue hypoxia in complex regional pain syndrome. Pain. 2003;104(1-2):14957. https://doi.org/10.1016/s0304-3959(02)00484-0.

177. Groeneweg JG, Huygen FJ, Heijmans-Antonissen C, Niehof S, Zijlstra FJ. Increased endothelin-1 and diminished nitric oxide levels in blister fluids of patients with intermediate cold type complex regional pain syndrome type 1. BMC Musculoskelet Disord. 2006;7(1):91. https://doi.org/10.1186/1471-2474-7-91.

178. Prough DS, McLeskey CH, Poehling GG, Koman LA, Weeks DB, Whitworth T, et al. Efficacy of oral nifedipine in the treatment of reflex sympathetic dystrophy. Anesthesiology. 1985;62(6):796-9. https://doi.org/10.1097/00000542-19850 6000-00017.

179. Inchiosa MA Jr, Kizelshteyn G. Treatment of complex regional pain syndrome type I with oral phenoxybenzamine: rationale and case reports. Pain Pract. 2008;8(2):125-32. https://doi.org/ 10.1111/j.1533-2500.2007.00170.x.

180. Muizelaar JP, Kleyer M, Hertogs IAM, DeLange DC. Complex regional pain syndrome (reflex sympathetic dystrophy and causalgia): management with the calcium channel blocker nifedipine and/or the $\alpha$-sympathetic blocker phenoxybenzamine in 59 patients. Clin Neurol Neurosurg. 1997;99(1):26-30. https://doi. org/10.1016/s0303-8467(96)00594-x.

181. Coward RM, Carson CC. Tadalafil in the treatment of erectile dysfunction. Ther Clin Risk Manag. 2008;4(6):1315-30. https:// doi.org/10.2147/tcrm.s3336.

182. Galiè N, Brundage BH, Ghofrani HA, Oudiz RJ, Simonneau G, Safdar Z, et al. Tadalafil therapy for pulmonary arterial hypertension. Circulation. 2009;119(22):2894-903. https://doi.org/10. 1161/CIRCULATIONAHA.108.839274.

183. Groeneweg G, Huygen FJ, Niehof SP, Wesseldijk F, Bussmann JB, Schasfoort FC, et al. Effect of tadalafil on blood flow, pain, and function in chronic cold complex regional pain syndrome: a randomized controlled trial. BMC Musculoskelet Disord. 2008;9(1):143. https://doi.org/10.1186/1471-2474-9-143.

184. Drummond ES, Maker G, Birklein F, Finch PM, Drummond PD. Topical prazosin attenuates sensitivity to tactile stimuli in patients with complex regional pain syndrome. Eur J Pain. 2016;20(6):926-35. https://doi.org/10.1002/ejp.817.

185. Russo MA, Santarelli DM. A novel compound analgesic cream (ketamine, pentoxifylline, clonidine, DMSO) for complex regional pain syndrome patients. Pain Pract. 2016;16(1):E1420. https://doi.org/10.1111/papr.12404.

186. Maihöfner C, Schneider S, Bialas P, Gockel H, Beer K-G, Bartels $\mathrm{M}$, et al. Successful treatment of complex regional pain syndrome with topical ambroxol: a case series. Pain management. 2018;8(6):427-36. https://doi.org/10.2217/pmt-2018-0048.

187. van Hilten JJ. Movement disorders in complex regional pain syndrome. Pain Med. 2010;11(8):1274-7. https://doi.org/10.1111/j. 1526-4637.2010.00916.x.

188. Maihöfner C, Baron R, DeCol R, Binder A, Birklein F, Deuschl $\mathrm{G}$, et al. The motor system shows adaptive changes in complex regional pain syndrome. Brain. 2007;130(Pt 10):2671-87. https://doi.org/10.1093/brain/awm131.

189. Azqueta-Gavaldon M, Schulte-Göcking H, Storz C, Azad S, Reiners A, Borsook D, et al. Basal ganglia dysfunction in complex regional pain syndrome-a valid hypothesis? Eur J Pain. 2017;21(3):415-24. https://doi.org/10.1002/ejp.975.

190. Mugge W, Munts AG, Schouten AC, van der Helm FC. Modeling movement disorders-CRPS-related dystonia explained by abnormal proprioceptive reflexes. J Biomech. 2012;45(1):90-8. https://doi.org/10.1016/j.jbiomech.2011.09.024.

191. van de Beek WJ, Vein A, Hilgevoord AA, van Dijk JG, van Hilten BJ. Neurophysiologic aspects of patients with generalized 
or multifocal tonic dystonia of reflex sympathetic dystrophy. J Clin Neurophysiol. 2002;19(1):77-83. https://doi.org/10.1097/ 00004691-200201000-00011.

192. Schwenkreis P, Janssen F, Rommel O, Pleger B, Volker B, Hosbach I, et al. Bilateral motor cortex disinhibition in complex regional pain syndrome (CRPS) type I of the hand. Neurology. 2003;61(4):515-9. https://doi.org/10.1212/wnl.61.4.515.

193. Punt DT, Cooper L, Hey M, Johnson MI. Neglect-like symptoms in complex regional pain syndrome: learned nonuse by another name? Pain. 2013;154(2):200-3. https://doi.org/10.1016/j.pain. 2012.11.006.

194. Melcangic M, Bowery NG. GABA and its receptors in the spinal cord. Trends Pharmacol Sci. 1996;17(12):457-62. https://doi. org/10.1016/s0165-6147(96)01013-9.

195. van der Plas AA, Marinus J, Eldabe S, Buchser E, van Hilten JJ. The lack of efficacy of different infusion rates of intrathecal baclofen in complex regional pain syndrome: a randomized, double-blind, crossover study. Pain Med. 2011;12(3):459-65. https://doi.org/10.1111/j.1526-4637.2011.01065.x.

196. van Rijn MA, Munts AG, Marinus J, Voormolen JH, de Boer KS, Teepe-Twiss IM, et al. Intrathecal baclofen for dystonia of complex regional pain syndrome. Pain. 2009;143(1-2):41-7. https:// doi.org/10.1016/j.pain.2009.01.014.

197. van der Plas AA, van Rijn MA, Marinus J, Putter H, van Hilten JJ. Efficacy of intrathecal baclofen on different pain qualities in complex regional pain syndrome. Anesth Analg. 2013;116(1):211-5. https://doi.org/10.1213/ANE.0b013e3182 6f0a2e.

198. Delhaas EM, Huygen F. Complications associated with intrathecal drug delivery systems. BJA Educ. 2020;20(2):51-7. https:// doi.org/10.1016/j.bjae.2019.11.002.

199. van Hilten JJ, van de Beek WJ, Vein AA, van Dijk JG, Middelkoop HA. Clinical aspects of multifocal or generalized tonic dystonia in reflex sympathetic dystrophy. Neurology. 2001;56(12):1762-5. https://doi.org/10.1212/wnl.56.12.1762.

200. Bhatia KP, Bhatt MH, Marsden CD. The causalgia-dystonia syndrome. Brain. 1993;116(Pt 4):843-51. https://doi.org/10.1093/ brain/116.4.843.

201. Knutsson E, Lindblom ULF, Mårtensson A. Plasma and cerebrospinal fluid levels of baclofen (Lioresal ${ }^{\circledR}$ ) at optimal therapeutic responses in spastic paresis. J Neurol Sci. 1974;23(3):473-84. https://doi.org/10.1016/0022-510x(74)90163-4.

202. Siongco PRL, Rosales RL, Moore AP, Freynhagen R, Arimura $\mathrm{K}$, Kanovsky $\mathrm{P}$, et al. Botulinum neurotoxin injections for muscle-based (dystonia and spasticity) and non-muscle-based (neuropathic pain) pain disorders: a meta-analytic study. J Neural Transm (Vienna). 2020;127(6):935-51. https://doi.org/10.1007/ s00702-020-02163-5.

203. Schilder JC, van Dijk JG, Dressler D, Koelman JH, Marinus $\mathrm{J}$, van Hilten JJ. Responsiveness to botulinum toxin type A in muscles of complex regional pain patients with tonic dystonia. J Neural Transm (Vienna). 2014;121(7):761-7. https://doi.org/ 10.1007/s00702-014-1172-8.

204. Kharkar S, Ambady P, Venkatesh Y, Schwartzman RJ. Intramuscular botulinum toxin in complex regional pain syndrome: case series and literature review. Pain Physician. 2011;14(5):419-24.

205. Lessard L, Bartow MJ, Lee J, Diaz-Abel J, Tessler OES. Botulinum toxin A: a novel therapeutic modality for upper extremity chronic regional pain syndrome. Plast Reconstr Surg Glob Open. 2018;6(10):e1847. https://doi.org/10.1097/GOX.0000000000 001847.

206. Safarpour D, Salardini A, Richardson D, Jabbari B. Botulinum toxin A for treatment of allodynia of complex regional pain syndrome: a pilot study. Pain Med. 2010;11(9):1411-4. https://doi. org/10.1111/j.1526-4637.2010.00897.x.

207. Huygen FJPM, Kleef M, Vissers KCP, Zuurmond WWA. Handboek pijngeneeskunde: De Tijdstroom; 2014.

208. Moretti A, Gimigliano F, Paoletta M, Liguori S, Toro G, Aulicino $\mathrm{M}$, et al. Efficacy and effectiveness of physical agent modalities in complex regional pain syndrome type I: a scoping review. Appl Sci. 2021;11(4):1857. https://doi.org/10.3390/app11041857

209. Bharwani KD, Dirckx M, Stronks DL, Dik WA, Huygen F. Serum soluble interleukin-2 receptor does not differentiate complex regional pain syndrome from other pain conditions in a tertiary referral setting. Mediators Inflamm. 2020;2020:6259064. https://doi.org/10.1155/2020/6259064.

210. Lenz M, Uceyler N, Frettloh J, Hoffken O, Krumova EK, Lissek $\mathrm{S}$, et al. Local cytokine changes in complex regional pain syndrome type I (CRPS I) resolve after 6 months. Pain. 2013;154(10):2142-9. https://doi.org/10.1016/j.pain.2013.06. 039 .

211. Birklein F, Ajit SK, Goebel A, Perez R, Sommer C. Complex regional pain syndrome-phenotypic characteristics and potential biomarkers. Nat Rev Neurol. 2018;14(5):272-84. https://doi. org/10.1038/nrneurol.2018.20. 